ARTICLE

https://doi.org/10.1038/s41467-020-14478-8

\title{
Chronic activation of endothelial MAPK disrupts hematopoiesis via NFKB dependent inflammatory stress reversible by SCGF
}

Pradeep Ramalingam, Michael G. Poulos², Elisa Lazzari², Michael C. Gutkin², David Lopez', Christopher C. Kloss' ${ }^{1}$, Michael J. Crowley', Lizabeth Katsnelson'1, Ana G. Freire², Matthew B. Greenblatt ${ }^{3}$, Christopher Y. Park ${ }^{4} \&$ Jason M. Butler $2,5 *$

Inflammatory signals arising from the microenvironment have emerged as critical regulators of hematopoietic stem cell (HSC) function during diverse processes including embryonic development, infectious diseases, and myelosuppressive injuries caused by irradiation and chemotherapy. However, the contributions of cellular subsets within the microenvironment that elicit niche-driven inflammation remain poorly understood. Here, we identify endothelial cells as a crucial component in driving bone marrow (BM) inflammation and HSC dysfunction observed following myelosuppression. We demonstrate that sustained activation of endothelial MAPK causes NF-KB-dependent inflammatory stress response within the BM, leading to significant HSC dysfunction including loss of engraftment ability and a myeloid-biased output. These phenotypes are resolved upon inhibition of endothelial NF-KB signaling. We identify SCGF as a niche-derived factor that suppresses BM inflammation and enhances hematopoietic recovery following myelosuppression. Our findings demonstrate that chronic endothelial inflammation adversely impacts niche activity and HSC function which is reversible upon suppression of inflammation.

\footnotetext{
${ }^{1}$ Department of Medicine, Division of Regenerative Medicine, Weill Cornell Medical College, New York, NY 10065, USA. ${ }^{2}$ Center for Discovery and Innovation, Hackensack University Medical Center, Nutley, NJ 07110, USA. ${ }^{3}$ Pathology and Laboratory Medicine, Weill Cornell Medical College, New York, NY 10021, USA. ${ }^{4}$ Department of Pathology, New York University Langone Health, School of Medicine, New York, NY 10016, USA. ${ }^{5}$ Molecular Oncology Program, Georgetown University, Washington, DC 20057, USA. *email: jason.butler@hmh-cdi.org
} 
$\mathrm{n}$ outstanding question in stem cell biology is whether chronic inflammation within tissue-specific microenvironments impairs the ability of supportive niche cells to appropriately nurture their cognate stem cells ${ }^{1-3}$. In the context of hematopoiesis, inflammatory signals play key roles during diverse processes including embryonic specification of the hematopoietic stem cell (HSC) during development, emergency granulopoiesis during infections, and hematopoietic regeneration following transplantation ${ }^{4-8}$. On the other hand, sustained inflammation has been proposed as a key driver of agingassociated hematopoietic defects including loss of HSC selfrenewal ability, myeloid-biased differentiation, and a predisposition towards leukemias ${ }^{9-12}$. Growing evidence indicates that the crosstalk between hematopoietic cells and their supportive niche cells initiates and sustains chronic inflammation within the bone marrow (BM), although their precise contributions in this process remain unclear ${ }^{9-12}$. Within the $\mathrm{BM}$, endothelial cells (ECs) have been established as an integral component of the HSC-supportive perivascular niche and express a diverse array of HSC-regulatory factors ${ }^{13-24}$. Modulation of signaling pathways within ECs have been shown to impact HSC self-renewal and lineage-commitment decisions ${ }^{15,21,22}$. Additionally, ECs play a key role during chronic inflammation ${ }^{24,25}$ and have emerged as an important source of niche-derived inflammatory signals within the BM, including interleukin-1 (IL-1) and G-CSF ${ }^{10,26}$. Sustained endothelial inflammation has been implicated in the initiation of myeloproliferative diseases through the expression of G-CSF and tumor necrosis factor- $\alpha(\mathrm{TNF})^{27}$. However, signaling pathways mediating chronic endothelial inflammation within the BM microenvironment that impact niche activity and HSC function remain poorly understood.

Nuclear factor $-\kappa \mathrm{B}(\mathrm{NF}-\kappa \mathrm{B})$ and MAPK are the principal signaling pathways regulating chronic inflammatory responses within $\mathrm{ECs}^{25}$. However, their role in modulating inflammation within the BM endothelial niche and the concomitant impact on HSC function remains unexplored. Prior work from our group has shown that suppression of NF- $\mathrm{KB}$ signaling within ECs enhances steady-state hematopoiesis as well as regeneration following myelosuppression, in part by decreasing proinflammatory cytokines ${ }^{21}$. Recent reports suggest that endothelial MAPK likely plays an essential role during inflammatory processes including LPS-induced granulopoiesis and chronic vascular inflammation-associated atherosclerosis ${ }^{28,29}$. Utilizing an ex vivo niche model system, we have previously demonstrated that endothelial MAPK activation drives myeloid-biased differentiation of co-cultured HSCs at the expense of their self-renewal, features that are suggestive of an inflammatory stress ${ }^{15}$. Here, we sought to determine whether endothelial MAPK activation impacts BM inflammation, niche activity, and HSC function.

\section{Results}

Endothelial MAPK activation impairs HSC function and hematopoiesis. To examine whether endothelial MAPK activation affects hematopoiesis, we generated a mouse model wherein MAPK signaling is constitutively activated within ECs of adult mice. Mice carrying a Rosa26 Stop/Floxed MEK1DD cassette (an inducible S218D/S222D MAPKK1 mutant that renders ERKMAPK signaling constitutively active) were crossed to a tamoxifen-inducible cre transgenic mouse under the control of the adult EC-specific VE-cadherin promoter (Cdh5(PAC)creERT2) to generate CDH5-MAPK mice. To activate MAPK signaling in ECs, 6- to 10-week-old male and female mice were maintained on tamoxifen-impregnated feed $(250 \mathrm{mg} / \mathrm{kg})$ for 4 weeks and were allowed to recover for 4 weeks before experimental analysis. CDH5-MAPK mice displayed decreased BM cellularity and a decline in the frequency and absolute numbers of immunophenotypically defined HSCs (defined as $\mathrm{cKIT}^{+}$Lineage $\left.{ }^{N e g} \mathrm{CD}_{4}{ }^{-} \mathrm{SCA}^{+}{ }^{+} \mathrm{CD} 150^{+} \mathrm{CD} 48^{\mathrm{Neg}}\right)$, as well as hematopoietic stem and progenitor cells (HSPCs) including KLS cells $\left(\mathrm{CKIT}^{+}\right.$Lineage $\left.\mathrm{Neg}^{\mathrm{SCA}}{ }^{+}\right)$, multipotent progenitors (MPPs; $\mathrm{CKIT}^{+}$Lineage $\left.{ }^{\mathrm{Neg}} \mathrm{SCA}^{+}{ }^{+} \mathrm{CD} 150 \mathrm{Neg}^{\mathrm{N}} 48^{\mathrm{Neg}}\right)$, and hematopoietic progenitor cell subsets (HPC-1 and HPC-2 defined as $\mathrm{cKIT}^{+}$Lineage ${ }^{\mathrm{Neg}} \mathrm{SCA}^{+}{ }^{+} \mathrm{CD} 150{ }^{\mathrm{Neg} C D} 48^{+}$and $\mathrm{cKIT}^{+}$Lineage ${ }^{\mathrm{Neg}} \mathrm{SCA}^{+}{ }^{+} \mathrm{CD} 150^{+} \mathrm{CD} 48^{+}$, respectively), as compared to their littermate controls (Fig. 1a-d, Supplementary Fig. 1a, Source Data). The decline in HSPC frequency in CDH5-MAPK mice manifested as a functional loss of progenitor activity by methylcellulose-based colony assays (Fig. 1e). Competitive BM transplantation revealed that BM cells from CDH5-MAPK mice displayed diminished long-term engraftment and a significant myeloid-biased peripheral blood output (Fig. 1f, g). Limiting dilution transplantation assays confirmed that endothelial MAPK activation significantly reduced the frequency of bona fide longterm HSCs (LT-HSCs) that are able to give rise to stable (>4 months; >1\% CD45.2 engraftment), multi-lineage engraftment (Fig. 1h, i). Cell-cycle analysis demonstrated that HSCs and HSPCs from CDH5-MAPK mice displayed a loss of quiescence and increased apoptosis as compared to their littermate controls (Fig. 1j, k, Suppementary Fig. 1b-f). Taken together, these data demonstrate that chronic activation of endothelial MAPK adversely impacts steady-state hematopoiesis and HSC function.

Endothelial MAPK drives an NF-kB dependent inflammatory stress response. The hematopoietic defects observed in $\mathrm{CDH} 5$ $M A P K$ mice suggest that constitutive MAPK activation likely affects the integrity of the $\mathrm{BM}$ endothelial niche. Immunofluorescence analysis of the BM confirmed that MAPK activation led to disruption of the endothelial network, including an increase in vascular dilatation (Fig. 2a). Analysis of vascular integrity by Evan's Blue assay revealed that $C D H 5-M A P K$ mice develop a significant increase in BM vascular leakiness, indicative of a loss of vascular integrity (Fig. 2b-d). Notably, vascular dilation and enhanced leakiness are hallmarks of an inflammatory stress ${ }^{30}$. Plasma proteome analysis of CDH5-MAPK mice demonstrated significantly increased levels of inflammatory mediators, including sICAM, VCAM, and IL1b (Fig. 2e, Supplementary Table 1, Supplementary Data 1). Ingenuity Pathway Analysis of the differentially expressed proteins revealed that "Inflammatory Response" was the most significantly enriched disease process in CDH5-MAPK mice ( $P$ value $1.3 \times 10^{-13}$, Fisher's exact test, and activation $z$-score 2.32) (Fig. 2f), indicating that endothelial MAPK activation leads to an inflammatory stress response. It is well established that NF- $\kappa B$ signaling plays pivotal roles in driving inflammatory responses, and recent reports indicate that endothelial MAPK activation can lead to inflammation via downstream activation of canonical NF- $\kappa \mathrm{B}$ signaling $28,29,31,32$. To verify this possibility, we performed immunoblot analysis on BM-derived ECs (BMECs) of CDH5-MAPK mice which confirmed an increase in MEK1DD driven ERK1/2 phosphorylation (Fig. $2 \mathrm{~g}, \mathrm{~h}$ ) and revealed a modest but consistent increase in $\mathrm{p} 65$ phosphorylation with no significant changes in total I $\mathrm{Ba}$ levels. These features are indicative of sustained activation of $\mathrm{NF}-\kappa \mathrm{B}$ signaling wherein endogenous feedback mechanisms increase the synthesis of total I $\mathrm{BBa}$ levels ${ }^{33-35}$. Quantification of nuclear p65 levels by immunofluorescence analysis demonstrated an increase in nuclear p65 within BMECs of CDH5-MAPK mice, confirming activation of NF- $\mathrm{KB}$ signaling downstream of endothelial MAPK activation ${ }^{36}$ (Fig. 2i, j). Collectively, these findings suggested that increased NF- $\mathrm{BB}$ signaling within ECs of CDH5-MAPK mice drives an inflammatory stress response leading to vascular defects. 


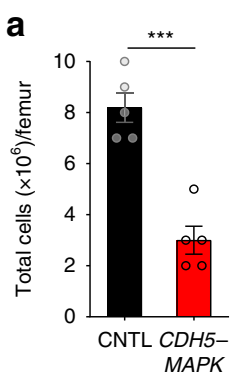

e

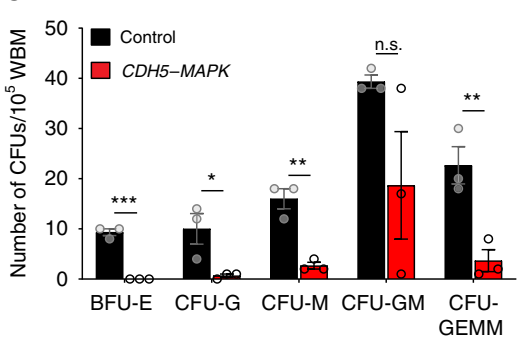

h

\begin{tabular}{|c|c|c|}
\hline \multicolumn{3}{|c|}{$\begin{array}{l}\text { Limiting dilution analysis } \\
\text { whole bone marrow }\end{array}$} \\
\hline & Cell dose & LTMR/recipient \\
\hline \multirow{3}{*}{ Control } & 50,000 & $3 / 10$ \\
\hline & 100,000 & $5 / 10$ \\
\hline & 250,000 & $10 / 10$ \\
\hline \multirow{3}{*}{$\begin{array}{l}\text { CDH5- } \\
\text { MAPK }\end{array}$} & 50,000 & $1 / 10$ \\
\hline & 100,000 & $4 / 10$ \\
\hline & 250,000 & $7 / 10$ \\
\hline
\end{tabular}

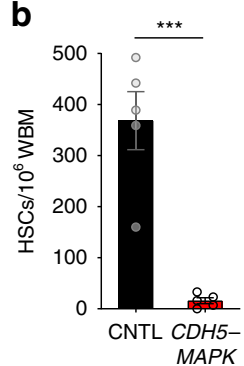

GEMM c

\section{i}

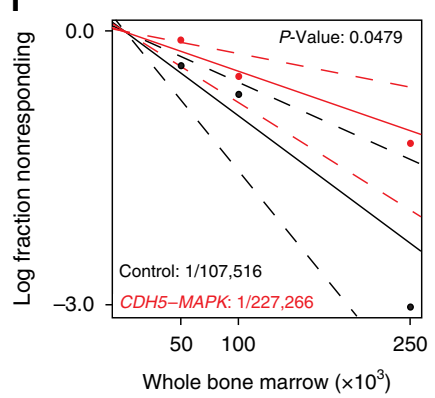

d

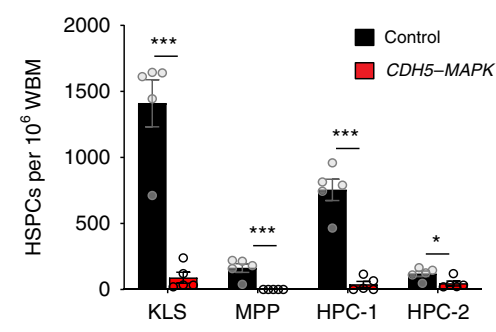

f

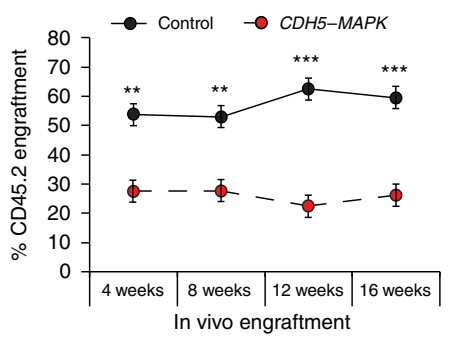

j

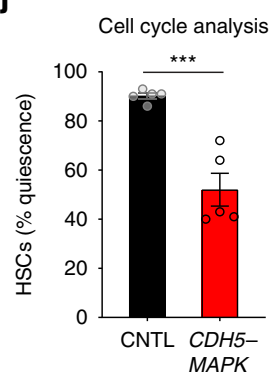

16 weeks post transplant

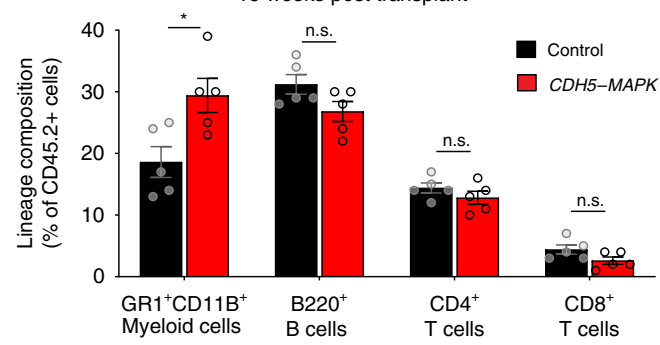

k

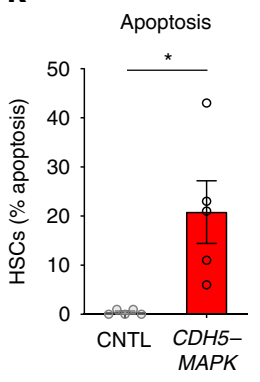

Fig. 1 CDH5-MAPK mice manifest HSC and hematopoietic defects. a Total cells per femur ( $n=5$ mice/cohort). $\mathbf{b}$ Frequency of phenotypic HSCs per $10^{6}$ femur cells assessed by flow cytometry ( $n=5$ mice/cohort). c Representative contour plots demonstrating gating strategy for quantification of BM HSC and HSPC frequency by flow cytometry. d Frequency of phenotypic HSPCs per $10^{6}$ femur cells assessed by flow cytometry ( $n=5$ mice/cohort).

e Methylcellulose-based progenitor assay. Bar graphs indicate number of CFUs per $10^{5}$ WBM ( $n=3$ mice/cohort). $\mathbf{f}$, $\mathbf{g}$ Competitive repopulation assays assessing total CD $45.2^{+}$cell engraftment and CD45.2+ lineage distribution over 4 months ( $n=10$ recipients/cohort; $n=5$ donors/cohort). For evaluating competitive repopulation, $5 \times 10^{5}$ donor WBM cells (CD45.2) were transplanted with $5 \times 10^{5}$ competitor WBM cells (CD45.1) into pre-conditioned CD45.1 recipient mice. $\mathbf{h}$ Table representing the number of recipients that were positive for long term, multi-lineage reconstitution (LTMR) following whole-bonemarrow-limiting dilution transplantation assay ( $n=10$ recipients/cohort per cell dose; $n=5$ donors/cohort). $\mathbf{i}$ Line graph displaying estimates of HSC frequency in the indicated genotypes with dashed lines representing $95 \%$ confidence intervals. Stem cell frequency and significance were determined using Extreme Limiting Dilution Analysis (ELDA). j Cell-cycle analysis of HSCs in the indicated genotypes by flow cytometry $(n=5$ mice/cohort). Gating strategy described in Supplementary Fig. 1b. k Quantification of HSC apoptosis in the indicated genotypes by flow cytometry ( $n=5$ mice/cohort). Gating strategy described in Supplementary Fig. 1b. Error bars represent sample mean \pm SEM. Statistical significance was determined using two-tailed unpaired Student's t-test. ${ }^{\star} P \leq 0.05 ;{ }^{\star \star} P<0.01 ;{ }^{\star \star \star} P<0.001 ;$ n.s. $P>0.05$.

Endothelial NF-kB inhibition resolves vascular defects in CDH5-MAPK mice. We next determined whether suppression of $\mathrm{NF}-\kappa \mathrm{B}$ signaling within ECs of $\mathrm{CDH} 5-\mathrm{MAPK}$ mice is sufficient to restore their vascular defects. To this end, we transduced BMECs derived from control and CDH5-MAPK mice with a lentivirus expressing a dominant negative $\mathrm{I} \kappa \mathrm{B} \alpha^{\mathrm{S} 32 \mathrm{~A} / \mathrm{S} 36 \mathrm{~A}}$ super-suppressor (IkB-SS) construct that sequesters NF-kB (p65/p50) in the cytoplasm $^{37,38}$. Immunoblot analysis confirmed the expression of IkB-SS transgene and revealed no significant alterations in ERK1/ 2 or p65 phosphorylation levels due to transgene expression (Fig. 3a, b). Immunofluorescence analysis confirmed that expression of IkB-SS decreased p65 nuclear translocation in BMECs of CDH5-MAPK mice (Fig. 3c, d). These findings suggested that increased NF- $\mathrm{kB}$ signaling within ECs of CDH5$M A P K$ mice in vivo could be suppressed by EC-specific expression of IkB-SS. To test this hypothesis, we crossed CDH5-MAPK mice with Tie2.IkB-SS mice (CDH5-MAPK::IkB mice) wherein the IkB-SS transgene is selectively expressed within ECs of adult mice $^{39}$. Analysis of NF- $\kappa \mathrm{B}$ regulated target gene expression within in vivo BMECs (defined as CD45-Ter119-CD31+VEcadherin+) of CDH5-MAPK mice revealed increased levels of NF-kB signaling targets, including the pro-inflammatory cytokines and chemokines Il1a, Illb, Cxcl1, Cxcl3, Ccl12, and Ccl22 (Fig. 3e-f, Supplementary Table 2). Importantly, BMECs derived from CDH5-MAPK::IkB mice demonstrated an overall decrease in expression of NF-kB target genes indicating that IkB-SS transgene expression within BMECs of CDH5-MAPK mice decreased their NF- $\kappa B$ signaling (Fig. 3e-f, Supplementary Table 2). Furthermore, immunofluorescence analysis of the BM endothelial niche demonstrated a normalization of the vascular dilation in $\mathrm{CDH} 5$ $M A P K:: I k B$ mice, confirming that inhibition of endothelial NF- $\kappa \mathrm{B}$ signaling is sufficient to restore $\mathrm{BM}$ vascular integrity in $\mathrm{CDH} 5$ MAPK mice (Fig. 3g). Collectively, these findings confirmed that the detrimental effects of endothelial MAPK activation on the BM 
a

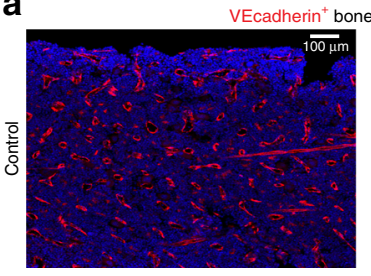

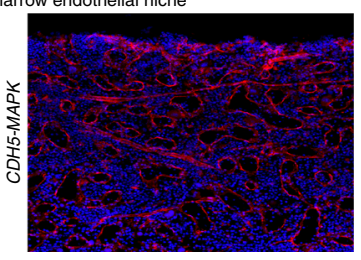

b

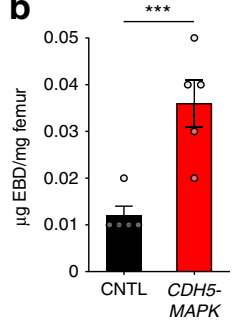

C

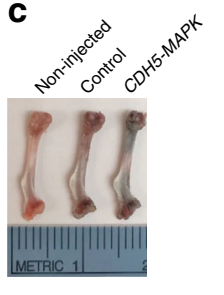

d

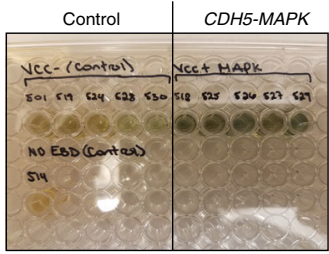

e

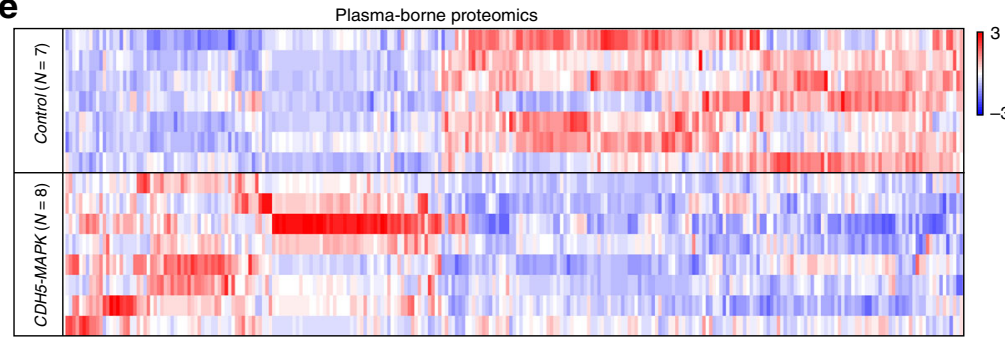

f

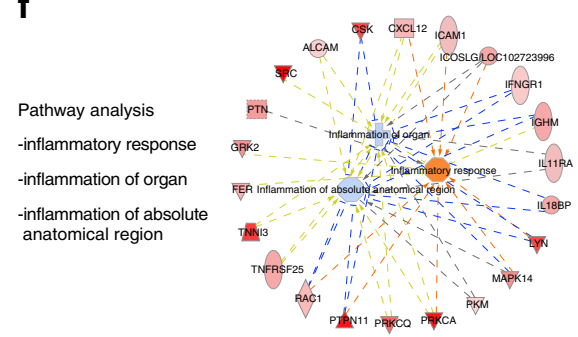

g

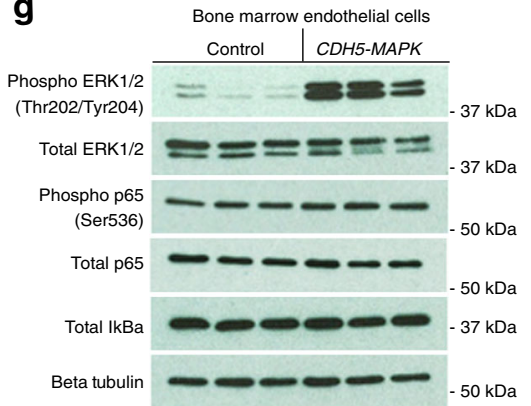

h

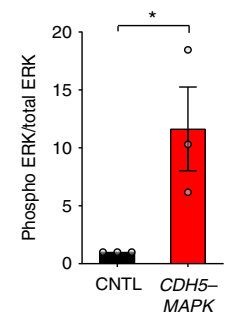

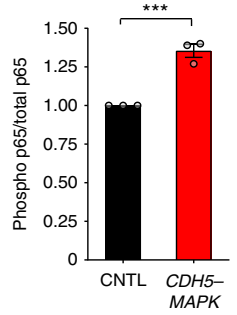

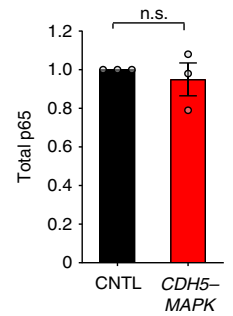

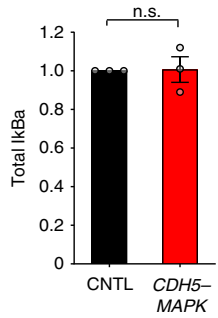

i

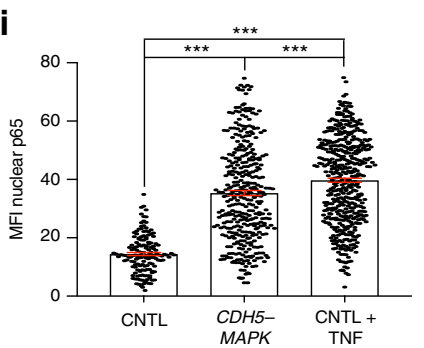

j
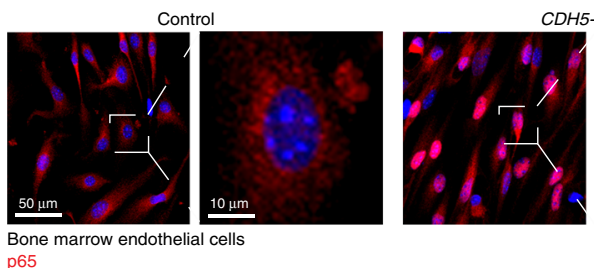

DHF-MAPK
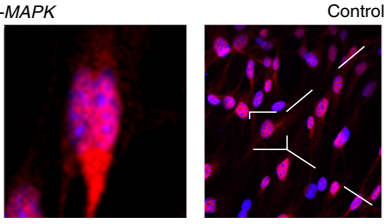

Control + TNF $\alpha$

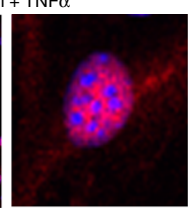

DNA

Fig. 2 CDH5-MAPK mice display systemic and BM-localized inflammation. a Representative immunofluorescence images of femurs intravitally labeled with a vascular-specific CD144/VE-cadherin antibody (red) demonstrating vascular dilatation in CDH5-MAPK mice. b Quantification of Evan's Blue Dye (EBD) extravasation ( $n=5$ mice/cohort). c Representative images of femurs isolated from mice injected with EBD. d Microtiter plate demonstrating intensity of extracted EBD for each sample. Non-injected controls were used to determine baselines. e Heatmap of 242 differentially expressed proteins in plasma of CDH5-MAPK mice identified by proteomic analysis ( $n=7$ control and $n=8 C D H 5-M A P K$ mice). Color scales represent relative protein abundance reflecting mean fluorescence intensities of SomaLogic aptamer-based ELISA. Raw data included in Supplementary Data 1 and Source Data. f Ingenuity Pathway Analysis of differentially expressed proteins demonstrating that inflammatory responses are over-represented in CDH5-MAPK mice. $\mathbf{g}, \mathbf{h}$ Immunoblot analysis of BMECs isolated from CDH5-MAPK mice demonstrating that MEK1DD expression in BMECs results in an increase in ERK1/2 and p65 phosphorylation ( $n=3$ biological replicates per genotype). $\mathbf{i}$, j Representative immunofluorescence images and quantification demonstrating increased levels of nuclear p65 in BMECs derived from CDH5-MAPK mice as compared to controls. Control BMECs treated with TNF $\alpha$ (10 ng/mL for 15 min) were used as a positive control for the assay. Each dot within the bar graph represents nuclear p 65 staining intensity per individual cell. Error bars represent sample mean \pm SEM. Statistical significance was determined using two-tailed unpaired Student's $t$-test. ${ }^{\star} P \leq 0.05 ;{ }^{\star \star \star} P<0.001 ;{ }^{n . s .} P>0.05$.

vascular niche are mediated primarily by downstream activation of endothelial NF- $\kappa \mathrm{B}$-dependent inflammatory stress.

Endothelial NF-кB inhibition restores HSC activity in CDH5$M A P K$ mice. We next determined whether restoration of $\mathrm{BM}$ endothelial niche integrity in CDH5-MAPK::IkB mice resulted in a functional recovery of HSCs and the hematopoietic system. Analysis of CDH5-MAPK::IkB mice demonstrated a restoration of BM cellularity and frequency of phenotypic HSCs and HSPCs (Fig. 4a, b, Supplementary Fig. 2a). The phenotypic recovery of progenitors within BM of CDH5-MAPK::IkB mice was also reflected in their progenitor activity in colony assays (Fig. 4c). Additionally, HSC functionality assayed by competitive BM transplantations demonstrated a complete recovery of long-term engraftment potential and a reversal of myeloid-biased differentiation in CDH5-MAPK::IkB mice (Fig. 4d, e, Supplementary Fig. 2b). WBM cells derived from CDH5-MAPK::IkB mice were also able to maintain their serial repopulation and multi-lineage reconstitution abilities during 
a

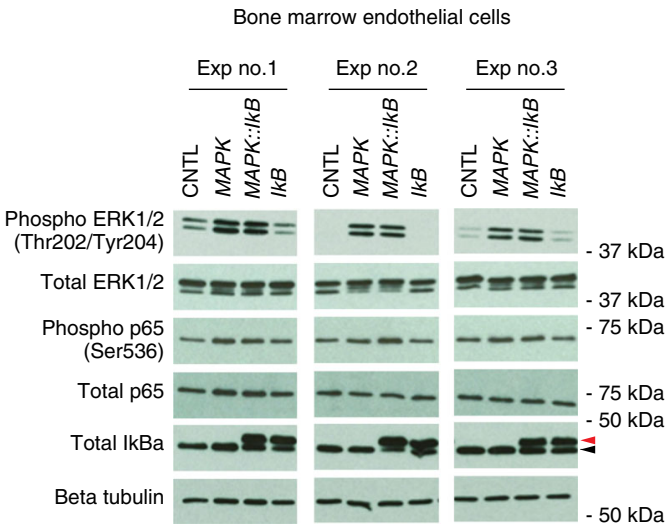

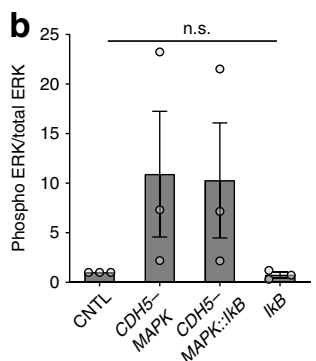
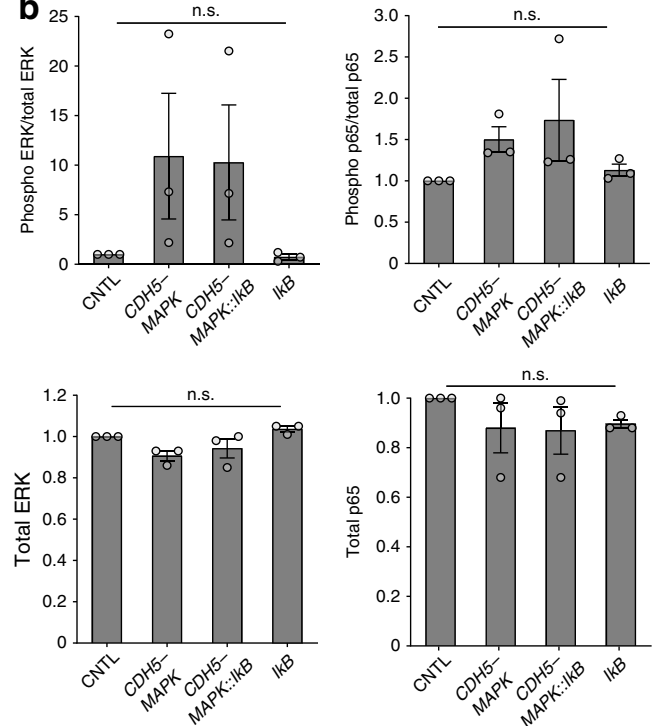
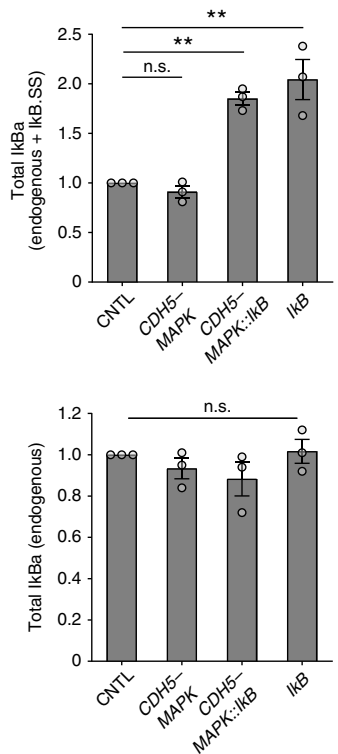

C

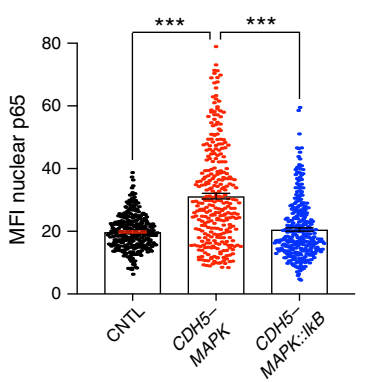

d
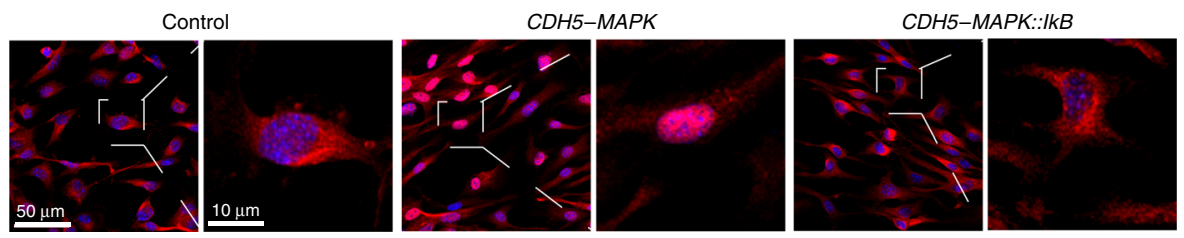

Bone marrow endothelial cells

p65

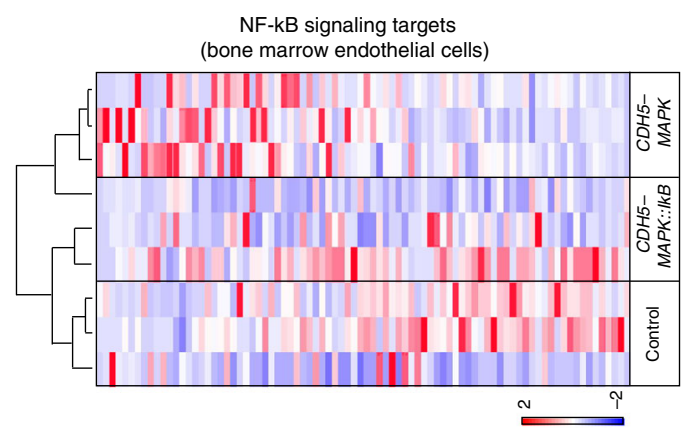

f

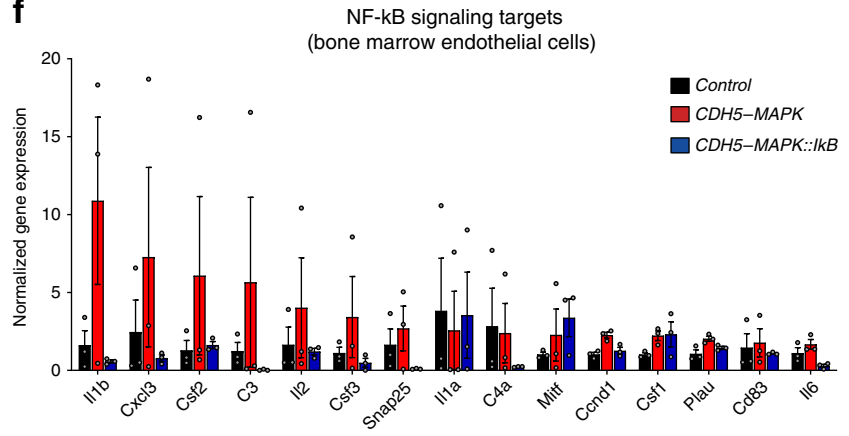

g

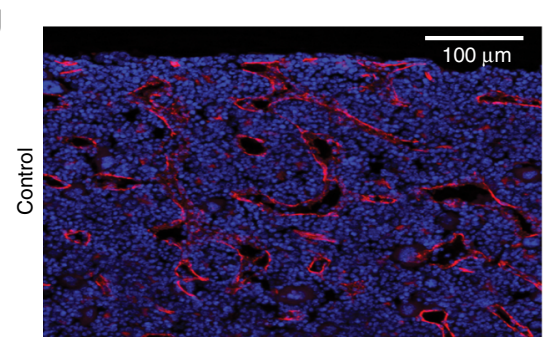

VEcadherin+ bone marrow endothelial niche

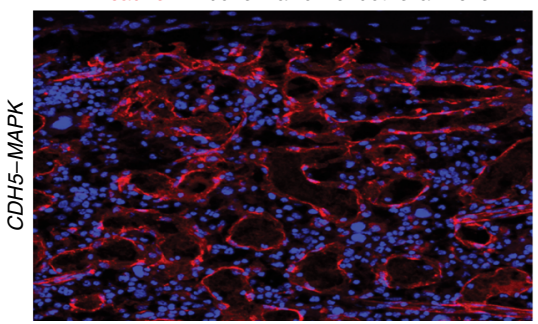

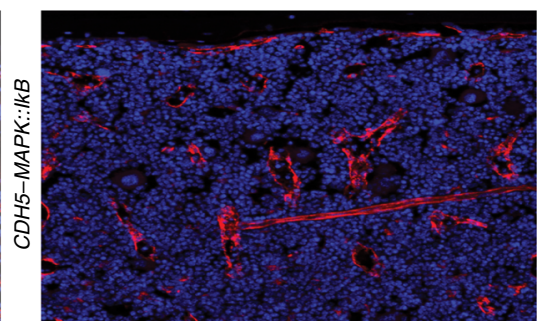

secondary transplantation assays (Supplementary Fig. 2c, d). Moreover, limiting dilution BM transplantation confirmed the restoration in frequency of bona fide LT-HSCs that were able to give rise to long-term multi-lineage engraftment in CDH5-MAPK:: $I \mathrm{kB}$ mice (Fig. 4f, g). Under homeostatic conditions, HSCs predominantly reside in a perivascular niche wherein they receive instructive cues from ECs and perivascular niche cells that regulate their quiescence and self-renewal. To determine whether inflammation within BMECs of CDH5-MAPK disrupted HSC-niche interactions, we performed whole-mount immunofluorescence imaging of HSCs which revealed an increase in average distance of HSCs from the vasculature (Fig. 4h, i). Notably, CDH5-MAPK::IkB mice demonstrated a restoration of HSC proximity to the vascular niche (Fig. 4h, i). These data demonstrate that rescue of $\mathrm{BM}$ endothelial integrity in $C D H 5-M A P K:: I k B$ mice resulted in a normalization of HSC-niche interactions and a restoration of HSC function. To determine whether inflammation associated with endothelial MAPK activation influences post-myelosuppressive 
Fig. 3 Endothelial NF-кB inhibition resolves endothelial inflammation and restores vascular integrity in CDH5-MAPK mice. a, b Immunoblot analysis and quantification demonstrating that expression of IkB-SS in BMECs isolated from CDH5-MAPK mice does not affect ERK1/2 or p65 phosphorylation. Black arrowhead represents endogenous I $\mathrm{KB} \alpha$ whereas red arrowhead represents IkB-SS transgene. c, $\mathbf{d}$ Representative immunofluorescence images and quantification demonstrating increased levels of nuclear p65 in BMECs derived from CDH5-MAPK mice as compared to controls. Note that expression of IkB-SS in BMECs isolated from CDH5-MAPK mice (CDH5-MAPK::IkB) decreases nuclear p65 levels. Each dot within the bar graph represents nuclear p65 staining intensity per individual cell. e, $\mathbf{f}$ Heatmap and bar graph demonstrating increased expression of NF- $\mathrm{kB}$-dependent inflammatory genes within BMECs of CDH5-MAPK mice. Crossing CDH5-MAPK with Tie2.IkB-SS mice (CDH5-MAPK::IkB) resulted in decreased expression of NF- $\mathrm{KB}-\mathrm{dependent} \mathrm{target}$ genes. Expression of Actb was used for normalization. Dendrograms represent unsupervised hierarchical clustering of the entire dataset $(n=3$ mice/ cohort). Color scales represent relative mRNA abundance based on normalized gene expression. Raw data for Heatmaps included in Supplementary Table 2 and Source Data. $\mathbf{g}$ Representative immunofluorescence images of femurs intravitally labeled with a vascular-specific CD144/VE-cadherin antibody (red) demonstrating that suppression of NF- $\mathrm{KB}$ signaling within endothelial cells of CDH5-MAPK mice resolves their vascular dilatation. Error bars represent sample mean $\pm \mathrm{SEM}$. One-way ANOVA for multiple comparisons and Tukey's correction was performed to determine significance. ${ }^{\star \star} P<0.01 ;{ }^{\star \star \star} P<0.001$; n.s. $P>0.05$

hematopoietic reconstitution, we subjected CDH5-MAPK, Tie2.IkBSS, and CDH5-MAPK::IkB mice and littermate controls to a sublethal myelosuppressive (650 Rad) injury. Peripheral blood analysis revealed that $C D H 5-M A P K$ mice displayed a significant delay in hematopoietic recovery, indicating that sustained endothelial MAPK activation is deleterious for recovery following myelosuppression (Fig. 4j). However, EC-specific NF- $\mathrm{kB}$ inhibition in $\mathrm{CDH} 5$ $M A P K$ mice protected white blood cell, neutrophil, red blood cell, and platelet loss following irradiation (Fig. 4j). Notably, the rate of hematopoietic recovery in CDH5-MAPK::IkB mice is similar to the recovery observed in Tie2.IkB-SS mice, which have been previously demonstrated to display a robust protection of the hematopoietic system following myelosuppressive injury ${ }^{21}$. These data suggest that endothelial inflammation in CDH5-MAPK mice delays hematopoietic recovery whereas EC-specific NF- $\mathrm{kB}$ inhibition in $\mathrm{CDH} 5$ $M A P K$ mice protects their hematopoietic compartment and enhances recovery following myelosuppressive injury.

Endothelial inflammation impairs hematopoietic progenitor activity. Along with HSCs, the vascular niche within the BM plays a crucial role in maintaining a diverse array of lineagecommitted hematopoietic progenitors that sustain steady-state peripheral blood output ${ }^{40-42}$. Moreover, the vascular niche within the spleen has been shown to be a vital component for extramedullary hematopoiesis ${ }^{43}$. We next sought to determine the effects of endothelial MAPK activation on hematopoietic progenitors within the $\mathrm{BM}$ and spleen. CDH5-MAPK mice displayed a decline in BM multipotent progenitors (MPPs), common lymphoid progenitors (CLP), common myeloid progenitors (CMPs), granulocyte/macrophage progenitors (GMPs), megakaryocyte/erythroid progenitors (MEPs), and B cell progenitor subsets (sIgM-B220+ B cells, Pre Pro B cells, Pro B cells, and Pre $B$ cells) which was functionally reflected in their decreased peripheral blood counts (Fig. 5a, b, d, Supplemetnary Fig. 2e, f). Hematopoietic cells within BM of CDH5-MAPK mice also manifested a myeloid-biased output (increased percentage of $\mathrm{CD} 11 \mathrm{~b}+\mathrm{GR} 1+$ cells within CD45+ BM cells), likely mediated by the effects of inflammatory cytokines that promote myeloidbiased differentiation of HSCs (Fig. 5c). The lineage-skewing in the $\mathrm{BM}$ was also reflected in their peripheral blood lineage composition (Fig. 5e). Collectively, these findings indicate that endothelial MAPK activation resulted in decreased blood counts due to loss of HSC and progenitor activity and was associated with a myeloid-biased output. Importantly, the BM and peripheral blood defects observed in CDH5-MAPK mice were completely restored in CDH5-MAPK::IkB mice. We next determined whether impaired hematopoiesis within BM of CDH5-MAPK mice could result in HSPC mobilization and extramedullary hematopoiesis. Peripheral blood analysis did not reveal significant differences in circulating KLS HSPCs demonstrating a lack of
HSPC mobilization in CDH5-MAPK mice (Fig. 5f). Analysis of the spleen in CDH5-MAPK mice revealed significant decreases in size and cellularity along with a decrease in frequency of HSCs and hematopoietic subsets, indicating an absence of extramedullary hematopoiesis (Fig. $5 \mathrm{~g}-\mathrm{k}$ ). Lineage composition of $\mathrm{CD} 45+$ cells in the spleen revealed a myeloid bias $(\mathrm{CD} 11 \mathrm{~b}+\mathrm{GR} 1+$ cells), confirming that endothelial MAPK-dependent inflammation adversely impacts niche activity and hematopoiesis within the spleen (Fig. 5l). Notably, CDH5-MAPK::IkB mice demonstrated a restoration of the defects observed in the spleen of CDH5-MAPK mice (Fig. 5g-l). These data demonstrate that CDH5-MAPK mice manifest hematopoietic defects, both in primary (bone marrow) and secondary (spleen) hematopoietic organs, and that suppression of endothelial NF- $\kappa \mathrm{B}$ signaling overrides the hematopoietic defects.

Endothelial MAPK activation drives an inflammatory stress response within the bone marrow. The HSC and hematopoietic defects along with the vascular dilation within BM of $\mathrm{CDH} 5$ $M A P K$ mice (Figs. 1 and 2) raised the possibility that downstream endothelial NF- $\kappa$ B activation induces a generalized inflammatory stress response within the BM microenvironment. In support of this idea, RT-qPCR analysis revealed an overall upregulation of NF-kB target genes in hematopoietic cells (CD45+), stromal cells (CD45-Ter119-CD31-VEcadherin-) as well as in unfractionated whole-bone marrow (WBM) cells of CDH5-MAPK mice (Supplementary Fig. 3a-f, Supplemetary Table 2, Source data), demonstrating that endothelial MAPK activation drives a generalized inflammatory response within the BM. The striking increase in expression of NF-kB target genes within the WBM of CDH5-MAPK mice (Supplementary Fig. 3e, f) raised the possibility of promiscuous expression of MEK1DD transgene within hematopoietic cells of CDH5-MAPK mice. To verify this possibility, we evaluated the fidelity of transgene expression in $\mathrm{CDH} 5$ $M A P K$ mice by using the endogenous Rosa26:eGFP reporter system to track cre-mediated recombination (Fig. 6). GFP expression was strictly confined to ECs within the bone marrow with no detectable expression in any of the hematopoietic subsets analyzed including HSCs as well as myeloid cells, B cells, and $\mathrm{T}$ cells (Fig. 6a-e, Supplementary Fig. 4a, b). Flow cytometric analysis demonstrated that tamoxifen administration resulted in activation of endothelial MAPK signaling in vivo (Fig. 6c), and also confirmed the fidelity of the GFP reporter system to track recombination efficiency (Fig. 6d). Moreover, RT-PCR analysis of FACS-sorted cells demonstrated that cre expression was restricted to ECs and not detected in hematopoietic cells of CDH5-MAPK mice (Fig. 6f, g). These findings confirm previous reports that Cdh5(PAC)-creERT2 mice demonstrate faithful endotheliumrestricted expression in adult mice, with no off-target expression in HSCs or hematopoietic cells ${ }^{44-47}$. We also confirmed that 

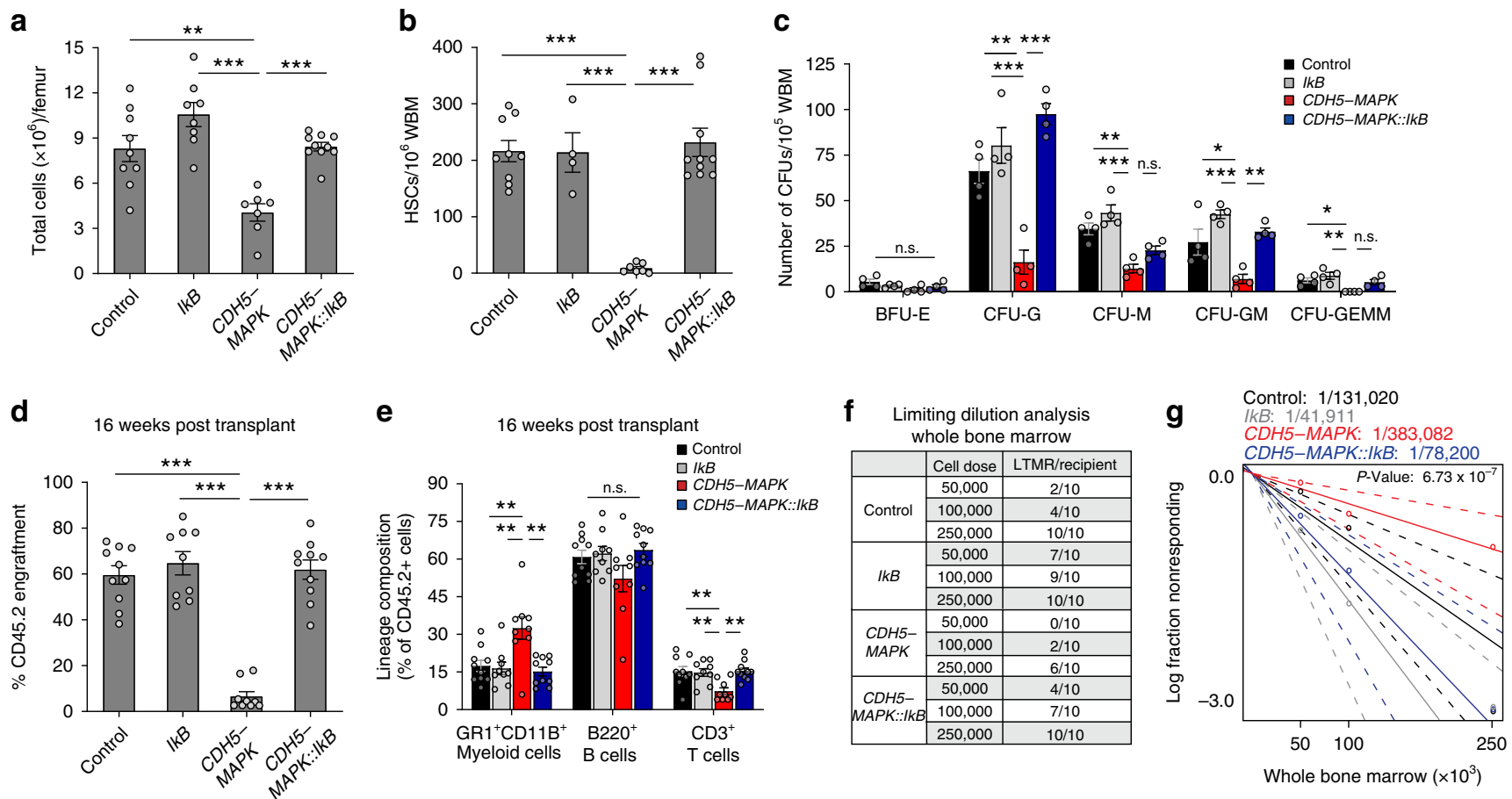

h
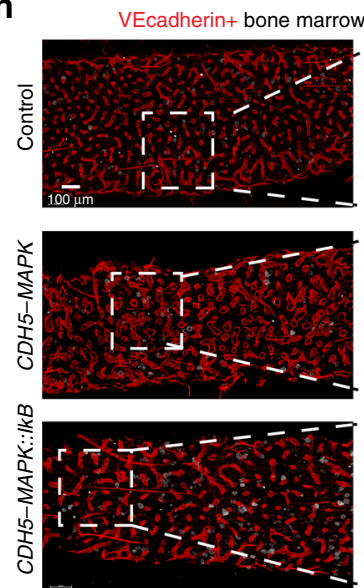

i
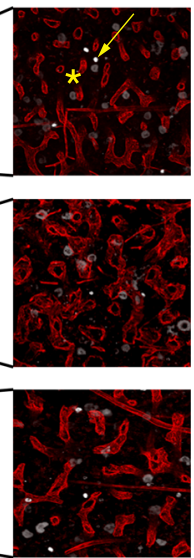

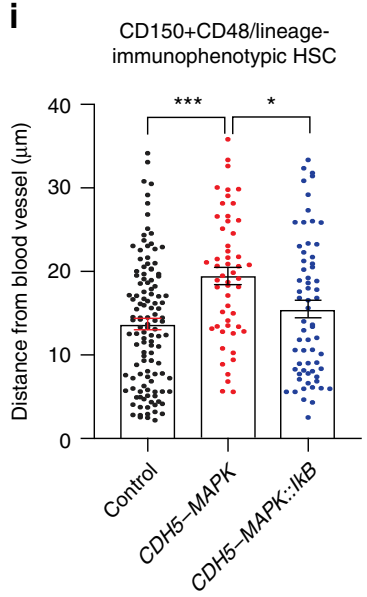

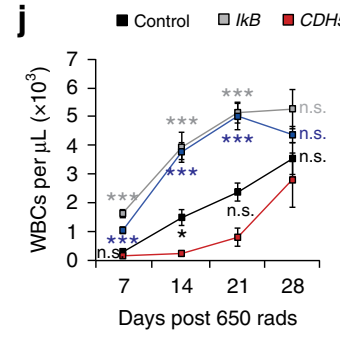

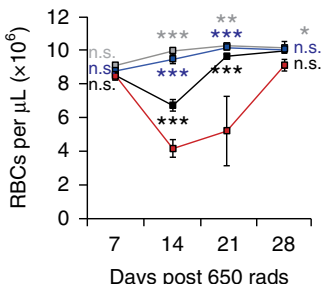

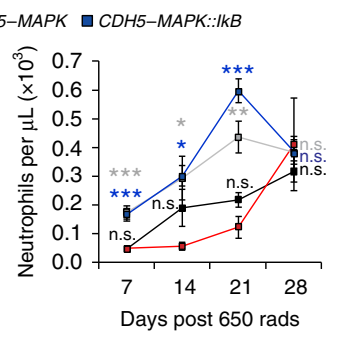

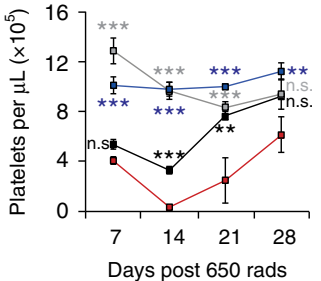

Fig. 4 Endothelial NF-KB inhibition restores HSC activity in CDH5-MAPK mice. a Total cells per femur ( $n=7-10$ mice/cohort). b Frequency of phenotypic HSCs per $10^{6}$ femur cells assessed by flow cytometry ( $n=7-10$ mice/cohort). Gating strategy described in Fig. 1b. c Methylcellulose-based progenitor assay. Bar graphs indicate number of CFUs per $10^{5} \mathrm{WBM}\left(n=4\right.$ mice/cohort). $\mathbf{d}$, e Competitive repopulation assays assessing total CD45.2 ${ }^{+}$ cell engraftment and CD45.2+ lineage distribution 4 months post-transplantation. For evaluating competitive repopulation, $5 \times 10^{5}$ donor WBM cells (CD45.2) were transplanted with $5 \times 10^{5}$ competitor WBM cells (CD45.1) into pre-conditioned CD45.1 recipient mice $(n=9-10$ recipients/cohort; $n=5$ donors per cohort). Gating strategy described in Supplementary Fig. 2b. $\mathbf{f}$ Table representing the number of recipients that were positive for long term, multi-lineage reconstitution (LTMR) following whole-bone-marrow-limiting dilution transplantation assay $(n=10$ recipients/cohort per cell dose, $n=5$ donors per cohort). $\mathbf{g}$ Log fraction plot of limiting dilution analysis indicates that CDH5-MAPK::IkB mice display an increase in frequency of HSCs capable of LTMR as compared to CDH5-MAPK mice. Dashed lines indicated $95 \%$ confidence intervals. Stem cell frequency and significance were determined using Extreme Limiting Dilution Analysis (ELDA). h, i Representative whole-mount immunofluorescence images of femurs and quantification of HSC distance from blood vessels of mice intravitally labeled with a vascular-specific CD144/VE-cadherin antibody (red) demonstrating that endothelial MAPK activation disrupts interactions of HSCs (white) with the vascular niche that are restored in CDH5-MAPK::IkB mice. Yellow arrowhead denotes a typical HSC (defined as Lineage ${ }^{\text {neg }}$ CD48 ${ }^{\text {neg }}$ CD150 bright) located in close proximity to a sinusoidal vessel. Yellow asterisk denotes a megakaryocyte. Each dot within the bar graph represents the distance of an individual HSC from its nearest blood vessel ( $n=3$ mice/cohort). $\mathbf{j}$ Time course of peripheral blood recovery following irradiation (650 rad) including red blood cells (RBCs). White blood cells (WBCs), platelets, and neutrophils $(n=6-10$ mice/cohort). The colors of significance asterisks represent comparisons of the indicated genotypes with CDH5-MAPK mice. Results demonstrate a myeloprotective effect in CDH5MAPK::IkB mice, indistinguishable from Tie2.IkB-SS mice. Error bars represent sample mean \pm SEM. One-way ANOVA for multiple comparisons and Tukey's correction was performed to determine significance. ${ }^{\star} P \leq 0.05 ;{ }^{\star \star} P<0.01 ;{ }^{\star \star \star} P<0.001 ;$ n.s. $P>0.05$. 
a
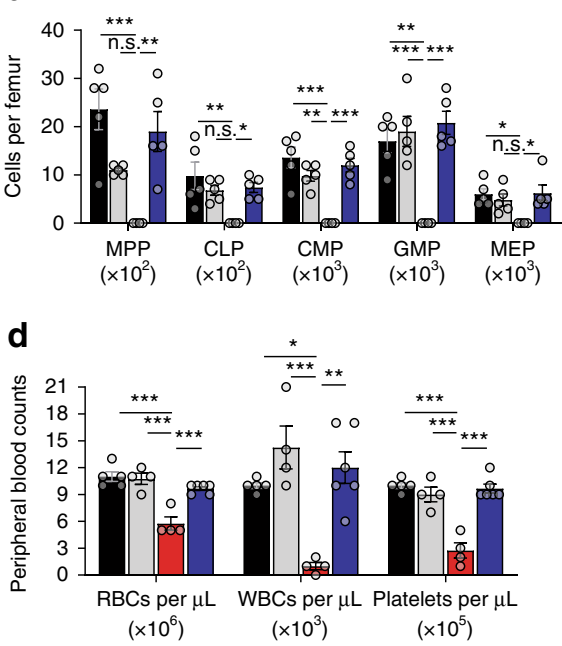

b
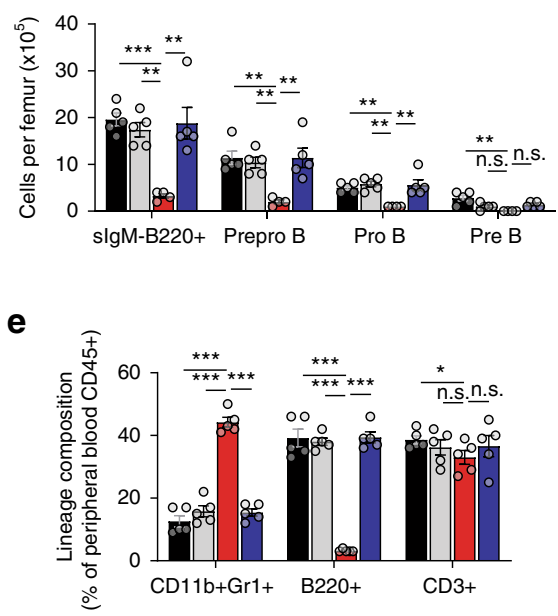

$\mathbf{h}$

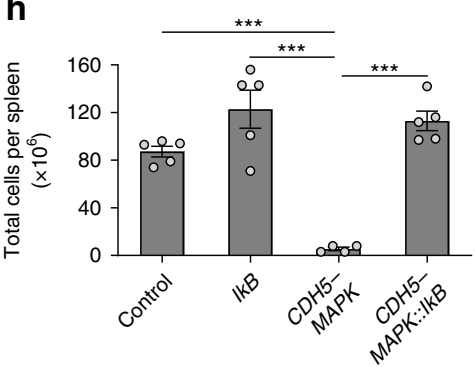

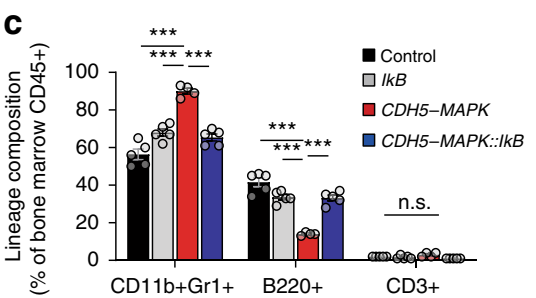

f

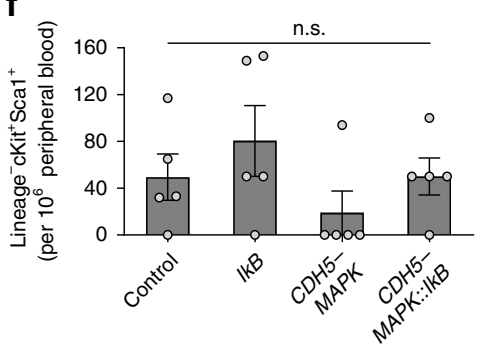

i

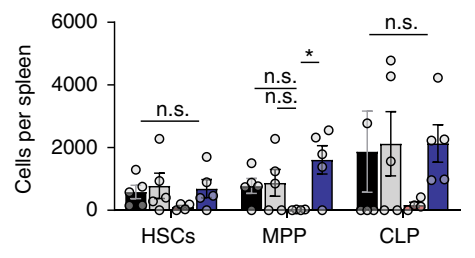

I

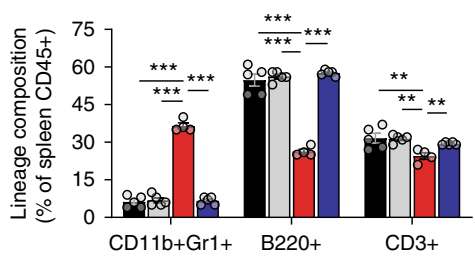

Fig. 5 Endothelial NF-KB inhibition restores hematopoietic progenitor activity in CDH5-MAPK mice. a, b Total cells per femur of the indicated hematopoietic progenitors estimated by flow cytometry $(n=4-5$ mice/cohort). Gating strategy described in Supplementary Fig. 2e, f. c Lineage composition of CD45+ cells within BM ( $n=4-5$ mice/cohort). d Steady-state peripheral blood counts ( $n=4-6$ mice/cohort). e Lineage composition of CD45+ cells within peripheral blood ( $n=5$ mice/cohort). $\mathbf{f H S P C}$ frequency in peripheral blood ( $n=5 \mathrm{mice} /$ cohort). $\mathbf{g}$ Gross images of spleen from the indicated genotypes. $\mathbf{h}$ Spleen cellularity in the indicated genotypes $(n=4-5 \mathrm{mice} / \mathrm{cohort})$. i-k Total cells per spleen of the indicated hematopoietic progenitors ( $n=4-5$ mice/cohort). I Lineage composition of CD45+ cells within spleen ( $n=4-5$ mice/cohort). Note that crossing CDH5-MAPK with Tie2. IKB-SS mice (CDH5-MAPK::IkB) restores the hematopoietic and HSPC attributes of CDH5-MAPK mice to control levels. Error bars represent sample mean \pm SEM. One-way ANOVA for multiple comparisons and Tukey's correction was performed to determine significance. ${ }^{\star} P \leq 0.05$; ${ }^{\star \star} P<0.01$; ${ }^{\star \star \star} P<0.001$; n.s. $p>0.05$.

expression of the IkB-SS transgene in Tie2.IkB-SS mice was restricted to ECs with no detectable expression in hematopoietic cells (Fig. 6f, g). The lack of Tie2-driven transgene expression in adult hematopoietic cells is consistent with previous reports ${ }^{48-51}$. Collectively, these observations confirm that HSC and hematopoietic defects in CDH5-MAPK mice are exclusively mediated from an endothelial NF- $\kappa B$-dependent inflammatory stress within the BM. Importantly, endothelial-specific suppression of NF- $\kappa \mathrm{B}$ signaling in CDH5-MAPK::IkB mice resolved the BM inflammation as indicated by unsupervised hierarchical clustering as well as the overall decrease in expression of NF-kB signaling targets (Supplementary Fig. 3a-f, Supplementary Table 2). Collectively, these results highlight that ECs, despite being a rare population within the BM (Fig. 6b), have a profound impact on HSC function and hematopoiesis during inflammatory stress.
Endothelial NF-кB inhibition resolves inflammation-induced hypoxic injury. The mechanisms by which BM inflammation impacts niche activity and HSC function remain poorly understood. Chronic inflammation is known to cause organ damage by inducing tissue hypoxia ${ }^{52-54}$. Furthermore, increased generation of reactive oxygen species (ROS) at sites of inflammation leads to endothelial dysfunction, vascular leakiness, and tissue injury ${ }^{55}$. Importantly, excessive ROS and hypoxia have been shown to adversely impact HSPC function by promoting loss of quiescence and exhaustion ${ }^{56-58}$. To this end, we examined the oxygenation status and ROS levels of HSPCs and BM niche cells (Fig. 7). HSPCs of CDH5-MAPK mice demonstrated a significant increase in hypoxia and ROS levels along with a loss of quiescence and increased apoptosis (Fig. 7a-d, Supplementary Fig. 5a, b). Notably, both BMECs and BM stromal cells also displayed increased 
a
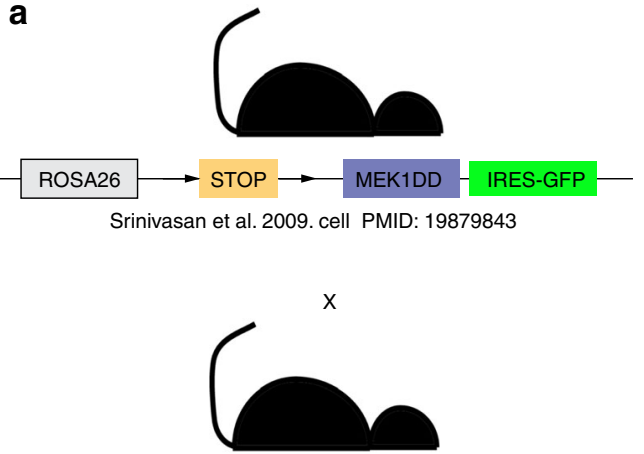

VEcadherin (CDH5) creERT2

Sorensen I, et al. 2009. blood PMID: 19144989 b

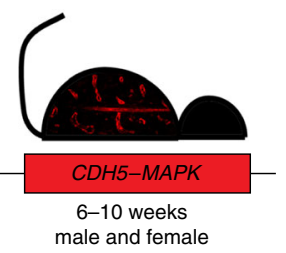

male and female

Control mice

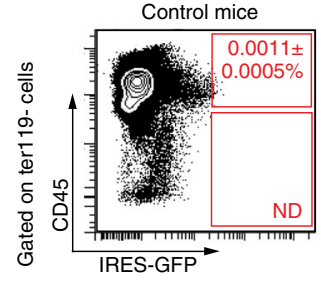

4 Weeks: tamoxifen feed

4 Weeks: recovery

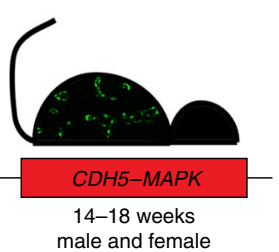

CDH5-MAPK mice

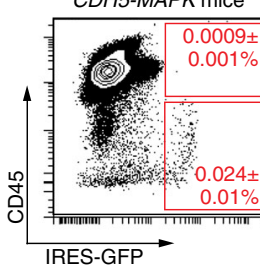

$\%$ BMECs of GFP+

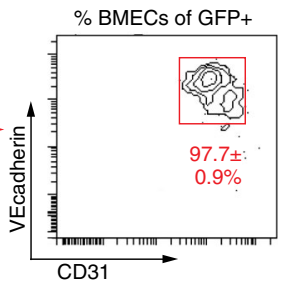

C

e
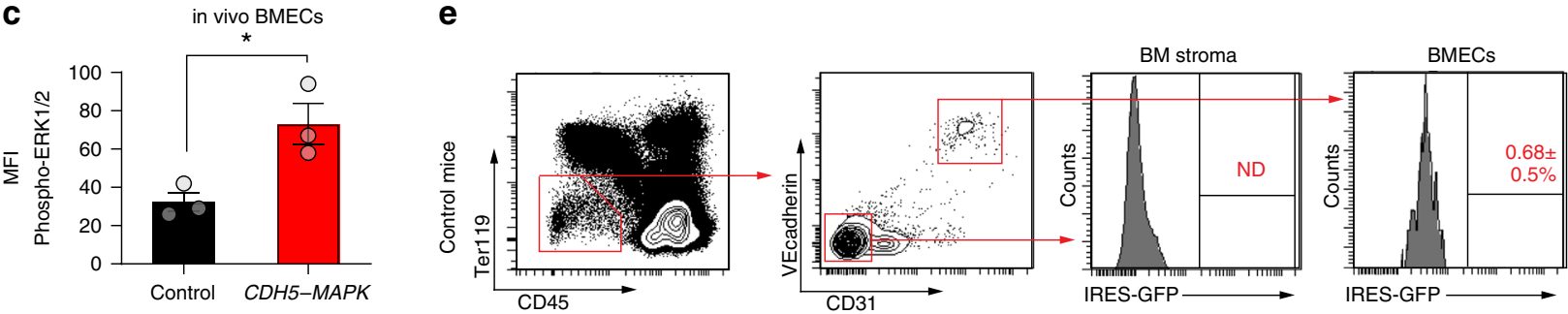

d CDH5-MAPK mice
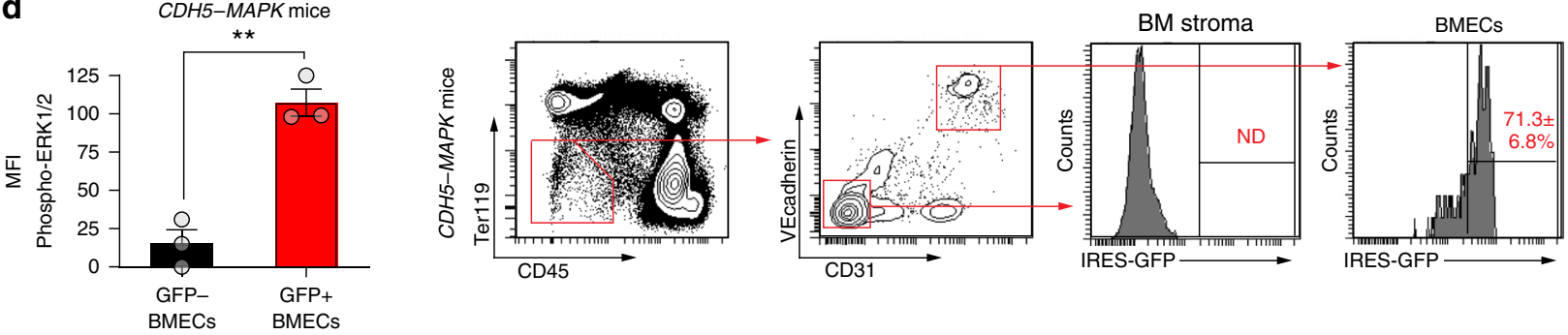

f

g
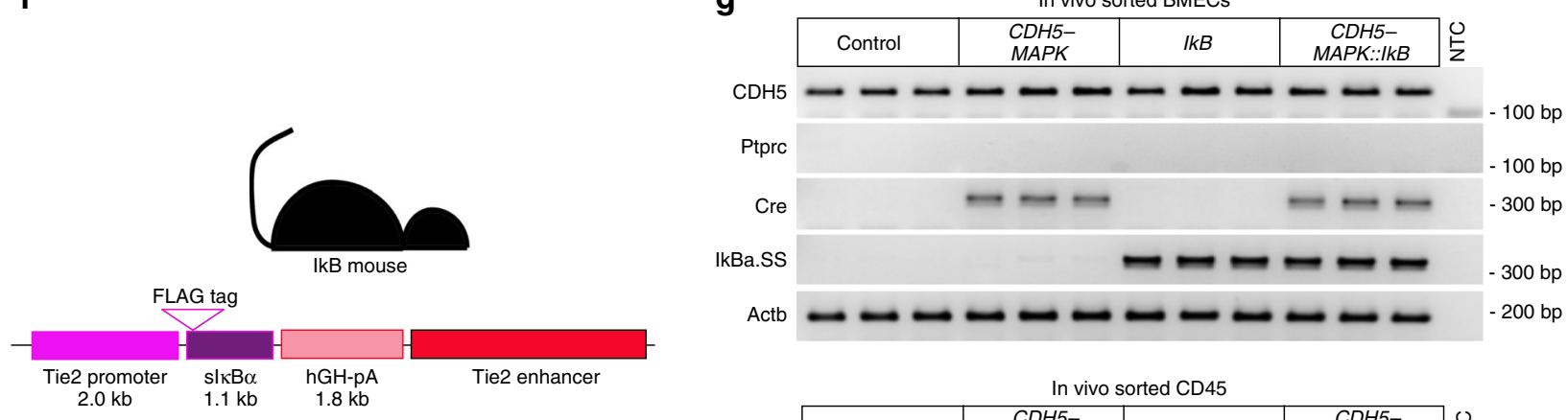

Kisseleva T, et al. 2006 JCI PMID: 17053836

Poulos M, et al. 2016. nature communications PMID: 28000664

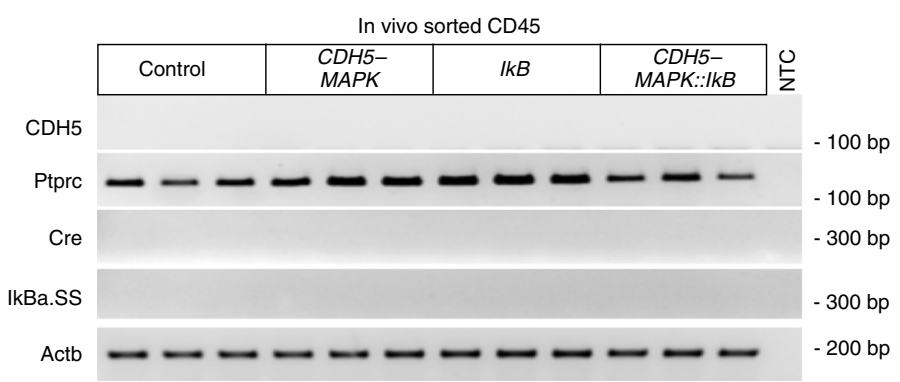

hypoxia (Fig. 7e), indicating that hypoxic injury induced by inflammation impacted both HSPCs and niche cells. Interestingly, niche cells did not display significant changes in ROS levels (Fig. 7f), indicative of a either a higher ROS detoxification ability or an impaired production in response to inflammatory stress.
However, BM stromal cells demonstrated a loss of cycling and increased apoptosis in CDH5-MAPK mice (Fig. 7g, h). Contrarily, the quiescent nature of BMECs observed under homeostasis was disrupted in CDH5-MAPK mice likely due to the direct effect of MAPK-driven cell-cycle entry (Fig. $7 \mathrm{~g}$ ). The alterations in 
Fig. 6 CDH5-MAPK and Tie2.IkB-SS mice demonstrate endothelial-specific expression of transgenes. a Schematic describing breeding strategy for generation of CDH5-MAPK mice. $\mathbf{b}$ Schematic describing Tamoxifen regimen before experimental analysis. Representative flow cytometry contour plots demonstrating GFP expression in whole-bone-marrow cells of CDH5-MAPK mice. Numbers indicate average frequency of cells in the indicated quadrants as the percentage of total BM cells \pm SEM ( $n=4-5$ mice/cohort). Note that GFP expression is detected exclusively in cells within the CD45- fraction of whole-bone-marrow cells and demonstrate surface expression of endothelial markers. c Analysis of phospho-ERK1/2 expression by flow cytometry confirms in vivo activation of the MAPK pathway in BMECs of CDH5-MAPK mice following Tamoxifen administration ( $n=3$ mice/cohort). $\mathbf{d}$ GFP + BMECs as compared to GFP- BMECs within CDH5-MAPK mice demonstrate increased phospho-ERK1/2 expression by flow cytometry, confirming the fidelity of GFP reporter for tracking cre-mediated recombination in vivo ( $n=3$ mice/cohort). e Endothelial cells within the BM of CDH5-MAPK mice (defined as CD45- Ter119- CD31+ VEcadherin+) demonstrate cre-mediated recombination whereas stromal cells (defined as CD45- Ter119- CD31- VEcadherin-) do not ( $n=4$ mice/cohort). $\mathbf{f}$ Schematic describing the Tie2.lkB-SS mouse model. $\mathbf{g}$ Agarose gel electrophoresis image of RT-PCR amplicons for the indicated genes using RNA isolated from FACS-sorted endothelial cells and CD45+ hematopoietic cells in the indicated genotypes ( $n=3$ mice/cohort). Note that IkB-SS transgene is expressed in endothelial cells and shows no detectable expression in hematopoietic cells. Also note the expression of cre transgene in endothelial cells of CDH5-MAPK mice and no detectable expression in hematopoietic cells. NTC denotes "No Template Control". Sort purity was confirmed using expression of Cdh5 (for endothelial cells) and Ptprc (for hematopoietic cells). Error bars represent sample mean \pm SEM. Statistical significance was determined using two-tailed unpaired Student's $t$-test. ${ }^{\star} P \leq 0.05$; ${ }^{\star \star} P<0.01$.

cell-cycle status of niche cells in CDH5-MAPK mice were reflected in their BM cellularity wherein BMECs displayed an increase in absolute numbers whereas stromal cells were reduced (Fig. 7i, k). Notably, the defects observed in niche cells of CDH5$M A P K$ mice were restored in CDH5-MAPK::IkB mice (Fig. 7e-h).

$\mathrm{BM}$ niche cells, including endothelium and various BM stromal subsets, are known to play critical roles in HSC maintenance by expressing pro-HSC factors such as KitL and SDF1 (ref. ${ }^{23}$ ). To determine whether endothelial MAPK activation altered the levels of these HSC-regulatory factors, we assessed their expression in candidate BM niche cells by RT-qPCR. However, no significant alterations in their expression were observed in either BMECs or BM stromal cells among the genotypes (Fig. 7j, l). Within the BM stromal population, Lepr+ cells (which include Nestin + and CXCL12-abundant reticular cells) have been shown to be an important source of KitL and SDF1 for HSC maintenance ${ }^{59}$. SDF1 is also known to be expressed by CD45-Ter119-CD31Sca1-CD51+ BM osteoblast cells ${ }^{60}$. Analysis of BM Lepr+ cells and osteoblasts did not reveal significant changes in their cellularity or in their expression of HSC-regulatory factors in CDH5-MAPK mice (Supplementary Fig. 6a-e, g, h). However, both Lepr+ cells and osteoblasts of CDH5-MAPK mice displayed an increased expression of NF- $\kappa \mathrm{B}$ regulated target genes similar to the other BM cellular subsets, which was suppressed upon inhibition of endothelial NF- $\mathrm{BB}$ signaling (Supplementary Fig. $6 \mathrm{f}$, i). Collectively, these results demonstrate that the niche and HSPC defects observed in CDH5-MAPK mice correlate with inflammation-induced alterations in ROS levels and hypoxia, and that inhibition of NF- $\mathrm{BB}$ signaling within ECs of CDH5-MAPK resolves these defects.

To identify pro-inflammatory genes that mediate HSPC and niche defects in CDH5-MAPK mice, we surveyed the qPCR-array data (Supplementary Table 2) for genes that showed increased expression within the BM endothelial, hematopoietic, and stromal compartments; Il1b, Csf1, Cdkn1a, and Csf2 were significantly upregulated in all three cellular subsets upon endothelial MAPK activation (Fig. $7 \mathrm{~m}$ ). Illb and Csf1 have been shown to directly impact HSC function and promote myeloid-biased differentiation ${ }^{10,61}$. Chronic Ill exposure has also been shown to cause enhanced HSC cycling and exhaustion ${ }^{10}$. The hematopoietic defects observed in CDH5-MAPK mice including increased HSPC cycling, impaired repopulating ability, and a myeloid-biased differentiation suggest that Illb and Csfl possibly mediate HSPC defects in CDH5-MAPK mice, and their suppression in CDH5-MAPK::IkB mice likely restores hematopoietic function. To verify this, we performed RT-qPCR analysis and confirmed that inhibition of endothelial NF- $\kappa \mathrm{B}$ signaling in CDH5-MAPK mice decreased the expression of Illb within
BMECs, stromal cells, and hematopoietic cells, while Csf1 expression was decreased in stromal cells and hematopoietic cells (Fig. $7 \mathrm{n}-\mathrm{p}$ ). Notably, the decrease in endothelial $I l 1 b$ expression correlated with a significant down-regulation of inflammation within the unfractionated WBM cells of $\mathrm{CDH}$ $M A P K:: I k B$ mice (Fig. 7q, Supplementary Fig. 3e), suggesting that endothelial $I l 1 b$ likely plays a key role in mediating BM inflammation in CDH5-MAPK mice. However, the diverse changes observed in the plasma proteome of CDH5-MAPK mice suggest that chronic inflammation possibly involves a balance of multiple pro- and anti-inflammatory mediators that regulate inflammatory responses and HSC function (Fig. 2e, f).

SCGF suppresses BM inflammation and restores HSC function in CDH5-MAPK mice. Given that crossing CDH5-MAPK mice to Tie2.IkB-SS mice resolved their inflammation and restored vascular and hematopoietic defects, we utilized these models to screen for candidate proteins that might regulate HSC function during inflammation. To this end, we performed a proteomic analysis on plasma derived from Tie2.IkB-SS mice and identified 82 proteins that were differentially expressed as compared to their littermate controls (Supplementary Table 3, Supplementary Data 1). We hypothesized that a potential pro-hematopoietic protein would display opposing trends in CDH5-MAPK mice as compared to Tie2.IkB-SS mice. Using this approach, we identified 18 candidate factors that were significantly altered and inversely correlated (i.e. down in CDH5-MAPK mice, up in Tie2.IkB-SS and vice versa) (Supplementary Fig. 7a, b). Among these, Clec11a/stem cell growth factor- $\alpha$ (SCGF) was the most significantly downregulated protein in CDH5-MAPK mice (Supplementary Fig. 7c). SCGF has recently been identified as a potential rejuvenation factor for restoration of bone formation in aged mice ${ }^{62}$. Although SCGF has been reported to be dispensable for steady-state hematopoiesis, plasma levels of SCGF have been reported to be downregulated in patients with severe malarial anemia and decreased levels of plasma SCGF correlated with poor hematopoietic recovery following bone marrow transplantation, indicating that SCGF could play key roles during stress hematopoiesis ${ }^{62-64}$. We confirmed the specificity of the SCGF aptamer and validated the observed decrease of plasma SCGF in $\mathrm{CDH}$ $M A P K$ mice (Supplemntary Fig. 7d). Notably, CDH5-MAPK::IkB mice displayed a restoration of their plasma SCGF levels, further indicating that SCGF could be a potential pro-hematopoietic factor that promotes recovery in CDH5-MAPK::IkB mice. (Supplementary Fig. 7e, f). To determine if SCGF can restore hematopoietic defects in CDH5-MAPK mice, we subcutaneously infused $4 \mu \mathrm{g}$ of SCGF for five consecutive days and analyzed phenotypic and functional attributes of their hematopoietic 

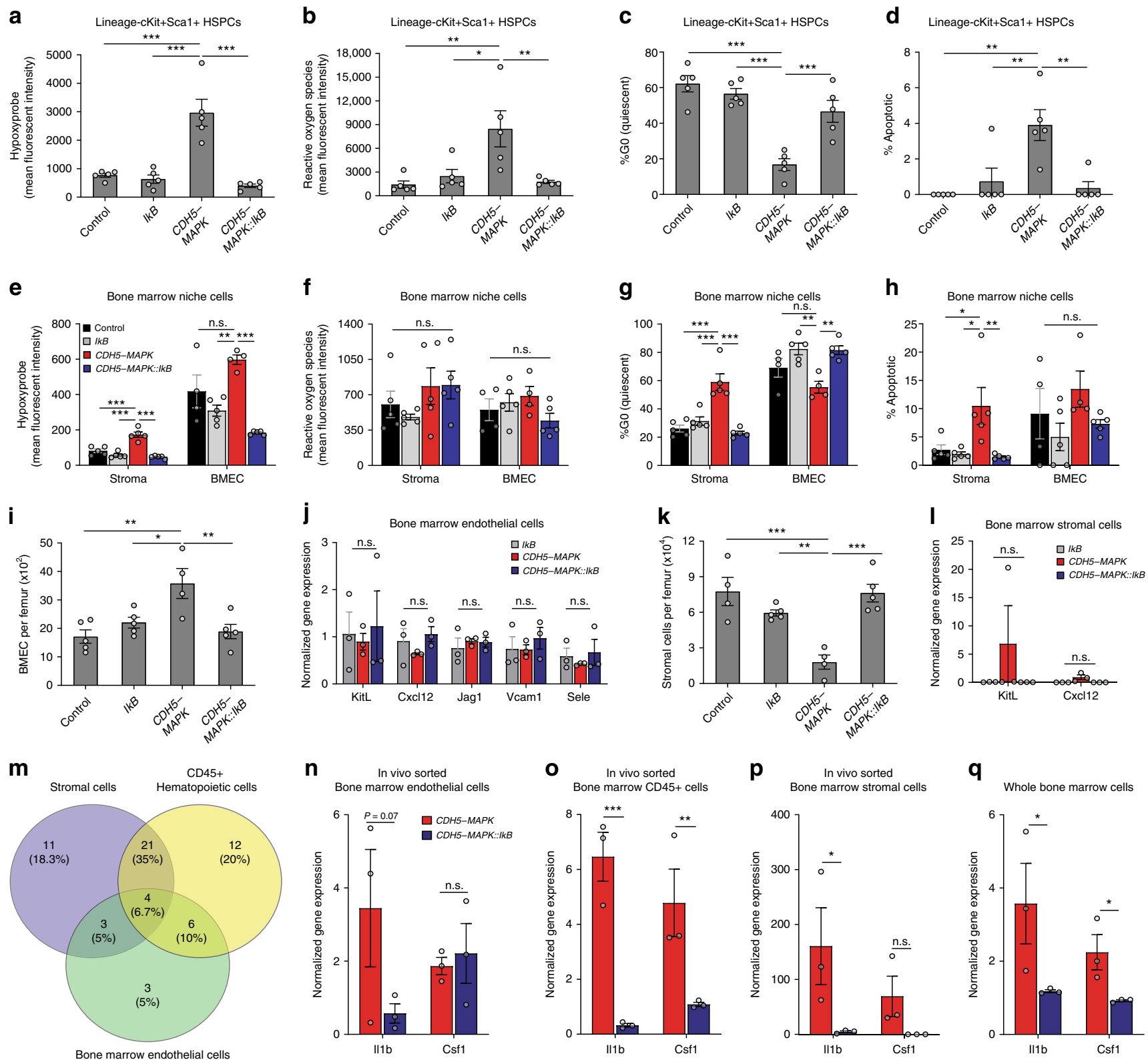

Fig. 7 Endothelial NF- $\mathbf{K B}$ inhibition rescues hypoxic injury of HSPCs and BM niche cells. a Estimation of oxygenation status in BM HSPCs based on quantification of hypoxyprobe by flow cytometry ( $n=5 \mathrm{mice} /$ cohort). Gating strategy described in Supplementary Fig. $5 \mathrm{a}$. b Quantification of ROS levels in HSPCs by flow cytometry-based quantification of CellROX orange ( $n=5$ mice/cohort). Note that CDH5-MAPK HSPCs display increased hypoxia and ROS levels that are resolved by crossing with Tie2.IkB-SS mice. Gating strategy described in Supplementary Fig. 5b. c Cell-cycle analysis of HSPCs based on Ki67-Hoechst staining by flow cytometry ( $n=5$ mice/cohort). $\mathbf{d}$ Quantification of apoptosis in HSPCs by quantification of the percentage of cells in the sub-G0/G1 phase by flow cytometry ( $n=5$ mice/cohort). HSPCs from CDH5-MAPK mice display a loss of quiescence and increased apoptosis that is resolved upon suppression of their endothelial NF- $\kappa B$ signaling. e-h Quantification of hypoxia, ROS levels, quiescence, and apoptosis in the indicated BM niche cells by flow cytometry ( $n=4-5$ mice/cohort). $\mathbf{i}$, $\mathbf{k}$ Estimation of BMECs and stromal cells per femur by flow cytometry ( $n=4-5$ mice/cohort).

j, I Expression of pro-HSC paracrine factors in FACS-sorted BM niche cells by RT-qPCR ( $n=3$ mice/cohort). Actb was used for normalization.

$\mathbf{m}$ Identification of commonly upregulated NF- $\mathrm{KB}$ target genes from QPCR-array data in BM stromal cells, hematopoietic cells, and ECs of CDH5-MAPK mice. n-q RT-qPCR confirmation of $111 b$ and Csf1 expression in the indicated cell types ( $n=3$ mice/cohort). Actb was used for normalization. Notice that inhibition of endothelial NF-KB signaling significantly suppresses the expression of II1b and Csf1 within the whole bone marrow of CDH5-MAPK mice. Error bars represent sample mean \pm SEM. One-way ANOVA for multiple comparisons and Tukey's correction was performed to determine significance.

${ }^{\star} P \leq 0.05 ;{ }^{\star \star} P<0.01 ;{ }^{\star \star \star} P<0.001 ;$ in.s. $P>0.05$.

system $24 \mathrm{~h}$ following the last injection (Supplementary Fig. 8a). SCGF infusion into littermate control mice confirmed that SCGF did not affect steady-state hematopoiesis as previously reported ${ }^{62}$ (Fig. 8, Supplementary Fig. 8). However, infusion of SCGF into CDH5-MAPK mice had profound effects on their hematopoiesis (Fig. 8a-e, Supplementary Fig. 8a-e). SCGF infusion resulted in a modest increase in BM cellularity (Supplementary Fig. 8b) and a significant increase in the frequency of phenotypic HSCs and HSPCs in CDH5-MAPK mice (Fig. 8a, b; Supplementary Fig. 8c). The increase in HSPC frequency was reflected in the enhanced colony-forming ability of BM cells isolated from SCGF-treated CDH5-MAPK mice (Fig. 8c). SCGF infusion also resolved the 
a

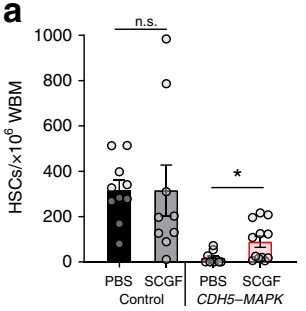

d

16 weeks post transplant
(primary transplant)

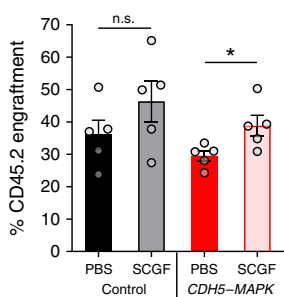

h

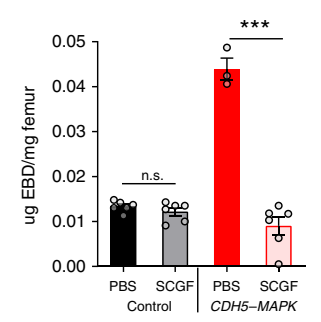

k

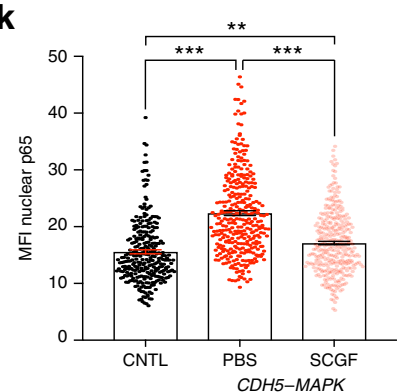

b

e

i
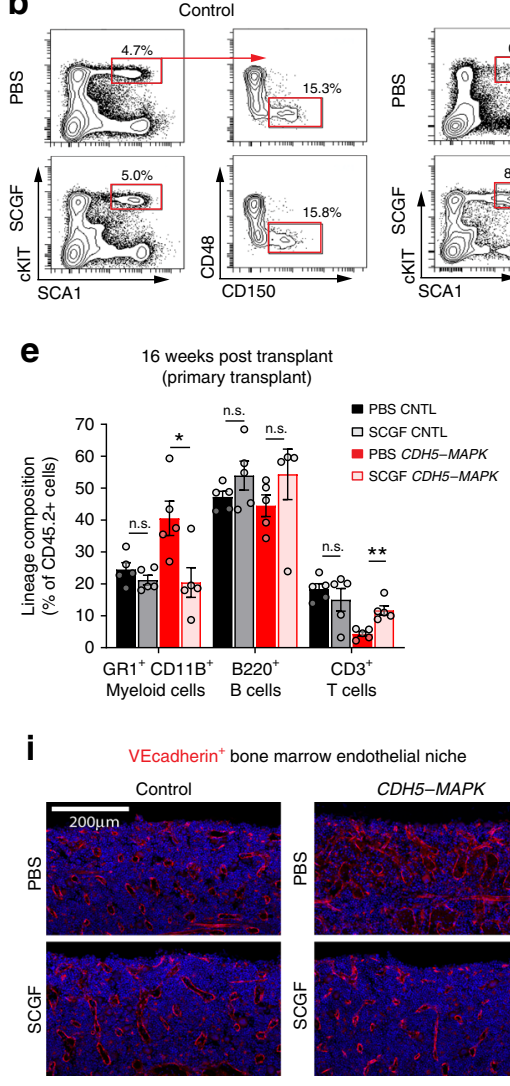

I

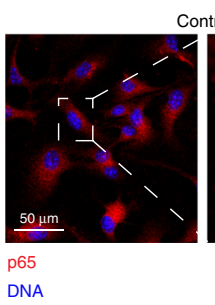

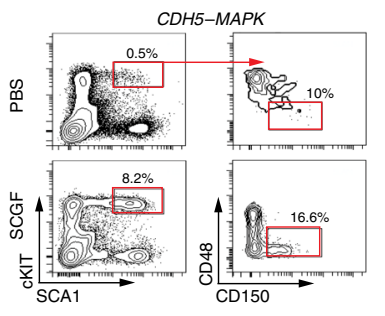

f 16 weeks post transplant (secondary transplant)
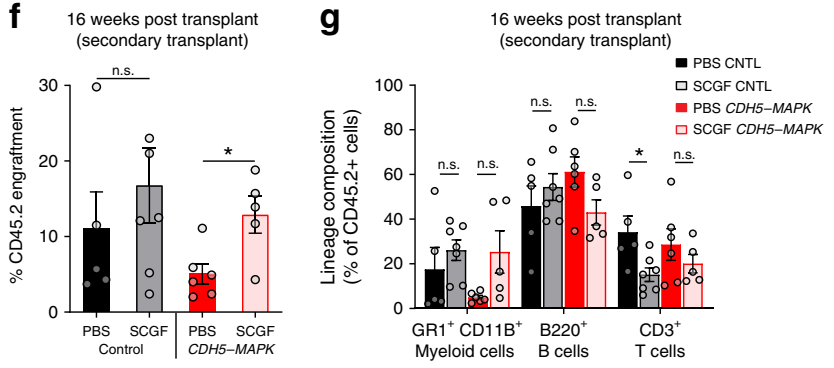

$\mathbf{j}$
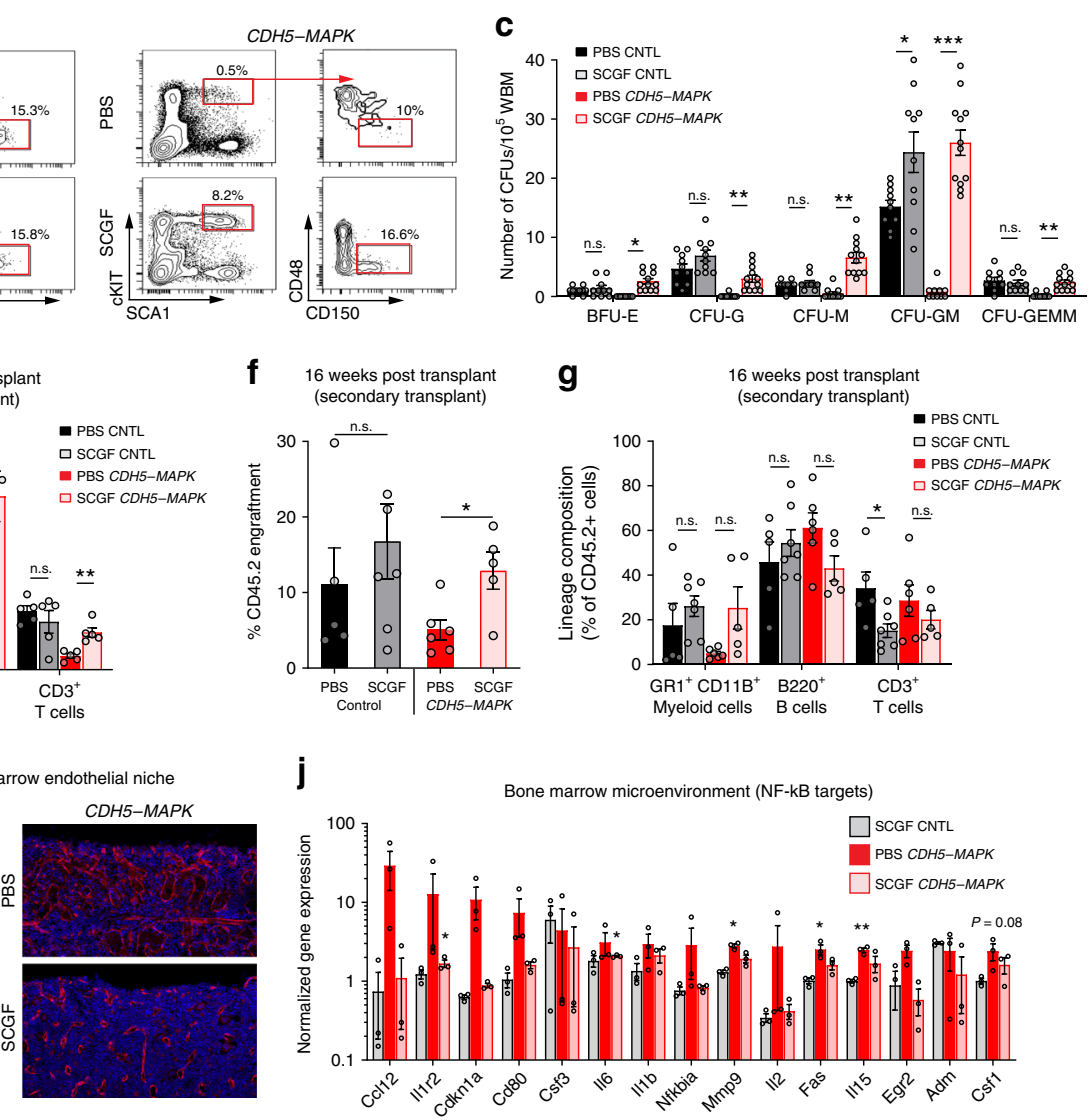

me marrow microenvironment (NF-kB targets)

$\square$ SCGF CNTL

$=0.08$ 
permanent and is reversible upon exposure to a wild-type BM microenvironment during serial transplantations (Fig. 8f, g).

Given that SCGF knockout mice display normal hematopoietic parameters and accelerated bone loss ${ }^{62}$, and the lack of discernible effects on hematopoiesis in SCGF-infused control mice (Fig. $8 \mathrm{a}-\mathrm{g}$ ), it is likely that the hematopoietic recovery observed in SCGF-infused CDH5-MAPK mice is possibly mediated by its effect on the vascular niche. Analysis of the endothelial niche revealed that infusion of SCGF resolved the vascular dilation and suppressed vascular leakiness within the BM microenvironment of CDH5-MAPK mice (Fig. 8h, i). The vascular recovery mediated by SCGF infusion was also associated with an overall decrease in expression of NF-kB target genes within the BM of CDH5-MAPK mice (Fig. 8j). The striking vascular recovery mediated by SCGF infusion raised the possibility that SCGF directly acts on the endothelium of CDH5-MAPK mice to suppress their NF-kB signaling. Immunofluorescence analysis demonstrated that SCGF treatment resulted in decreased nuclear p65 levels within BMECs isolated from CDH5-MAPK mice confirming a direct effect of SCGF on ECs (Fig. 8k, l). Taken together, these data indicate that infusion of SCGF into CDH5-MAPK mice suppresses endothelial inflammation and restores vascular integrity, which leads to a recovery of their hematopoietic system.

Since SCGF has been shown to promote osteogenesis, it is likely that the decrease in plasma SCGF levels along with the BM inflammation observed in CDH5-MAPK mice could result in osteopenia. CDH5-MAPK mice indeed displayed an overall decrease in trabecular bone volume, trabecular numbers, and thickness demonstrating that endothelial MAPK activation has a deleterious impact on bone health (Supplementary Fig. 9a-d). We next set forth to determine if SCGF could restore bone formation in CDH5-MAPK mice. Similar to its effects on hematopoiesis, SCGF did not affect bone formation in control mice (Supplementary Fig. 9a-d). However, infusion of SCGF caused a significant increase in trabecular bone volume and trabecular numbers and thickness in CDH5-MAPK mice, confirming its role in promoting osteogenesis (Supplementary Fig. 9a-d). Notably, SCGF expression was absent in hematopoietic cells and BMECs, and was primarily expressed in BM stromal cells including BM Lepr+ and osteoblastic stromal subsets (Supplementary Fig. 9e). Analysis of SCGF expression in total stromal cells, Lepr+ cells, and osteoblasts from BM of Tie2-IkB-SS, CDH5-MAPK, and CDH5-MAPK::IkB mice, however, revealed no significant changes in mRNA expression (Supplementary Fig. 9f), indicating that decreased plasma SCGF in CDH5-MAPK mice is not due to transcriptional alterations. It is known that cytokines mediating inflammatory responses can be regulated at the translational level and a recent report demonstrated that $I l 1 b$ regulates the secretory response of chondrocytes by regulating translation ${ }^{65,66}$. Given that SCGF is a secreted protein and appears to regulate inflammatory responses, it is likely that it might be subject to translational regulation. However, the most likely explanation for decreased plasma SCGF in CDH5-MAPK mice appears to be due to the overall decrease in BM stromal cell numbers (the cells producing plasma SCGF) in CDH5-MAPK mice due to their apoptosis. (Fig. 7h, k). Collectively, these data indicate that SCGF infusion restores hematopoietic defects observed in CDH5-MAPK mice by restoring vascular integrity, resolving $B M$ inflammation and improving bone health, thus suggesting that SCGF might play key roles in mediating hematopoietic recovery under stress situations.

SCGF enhances hematopoietic regeneration following myelosuppressive injury. Myelosuppressive insults have been shown to adversely impact the endothelial niche resulting in a loss of vascular integrity and delayed hematopoietic recovery ${ }^{13,67}$. In particular, ionizing radiation is known to activate NF-kB signaling within the endothelium leading to inflammation and endothelial dysfunction $^{68}$. Given that SCGF infusion resolves vascular and hematopoietic defects in CDH5-MAPK mice, we sought to determine whether SCGF can enhance hematopoietic recovery following myelosuppressive stress. Wild-type mice were given a myelosuppressive dose of irradiation (650 rad) and infused every other day with either $0.5,1$, or $2 \mu \mathrm{g}$ of SCGF for a total of seven injections starting at Day +1 post-irradiation and hematopoietic recovery was assessed for 21 days (Supplementary Fig. 10a). The dose-response experiment indicated that infusion of $2 \mu \mathrm{g}$ of SCGF resulted in a significantly enhanced recovery of white blood cells, red blood cells, and platelets, confirming that SCGF enhances hematopoietic recovery following myelosuppressive stress (Supplementary Fig. 10a). Utilizing this strategy, we sought to test whether SCGF can improve hematopoietic recovery and preserve HSPC activity in both control and CDH5-MAPK mice (Supplementary Fig. 10b). We found that infusion of SCGF improved hematopoietic recovery following 650 rad of myelosuppressive irradiation in both control and CDH5-MAPK mice (Fig. 9a, b). Immunofluorescence analysis of femoral BM sections at Day 28 post-irradiation revealed that SCGF infusion resulted in preservation of vascular integrity in both control as well as CDH5-MAPK mice (Fig. 9c, d). Evaluation of BM cellularity and HSC frequency after 28 days following myelosuppressive injury revealed that there was a significant increase in BM cellularity in both control and CDH5-MAPK mice treated with SCGF (Fig. 9e), while no significant changes were observed in phenotypic HSC frequency (Fig. 9f). Given that HSC frequency has been shown to poorly correlate with engraftment potential under conditions of inflammatory stress ${ }^{69}$, we set forth to determine if SCGF infusion enhances HSC functionality following myelosuppression. To this end, we performed a competitive BM transplant on day 28 postirradiation, wherein $2.5 \times 10^{6}$ donor WBM cells from $\mathrm{CDH}$ $M A P K$ mice or littermate controls (treated with phosphatebuffered saline (PBS) or SCGF) were transplanted along with $5 \times$ $10^{5}$ CD45.1 competitor WBM cells into lethally irradiated (950 rads) CD45.1 mice (Fig. 9g, h). Analysis of CD45.2 cell engraftment 4 months post-transplant revealed that infusion of SCGF significantly enhanced long-term engraftment potential and multi-lineage reconstitution abilities for hematopoietic cells derived from both control and CDH5-MAPK mice (Fig. 9g, h). SCGF infusion was able to maintain the serial repopulation ability of hematopoietic cells derived from CDH5-MAPK mice during secondary transplantation assays (Fig. $9 \mathrm{~g}, \mathrm{~h}$ ), demonstrating that SCGF preserves HSC functionality in CDH5-MAPK mice both at steady state (Fig. 8d-g) and following myelosuppressive injury (Fig. 9g-j). Although SCGF infusion did not impact steady-state hematopoiesis in control mice (Fig. 8), these data show that SCGF preserves HSC function in control mice following myelosuppressive injury (Fig. 9g, h), thereby uncovering an undefined role for SCGF during hematopoietic stress. Collectively, these findings demonstrate that SCGF has potent therapeutic properties that not only enhances vascular and hematopoietic recovery under an inflammatory stress, but also significantly improves the functionality of the HSC following myelosuppressive insult to the hematopoietic system.

\section{Discussion}

The direct effects of specific inflammatory cytokines on HSC function have been extensively investigated ${ }^{70}$. However, the impact of chronic inflammation on HSC-supportive niche cells within the BM microenvironment remains poorly understood due to the 
a
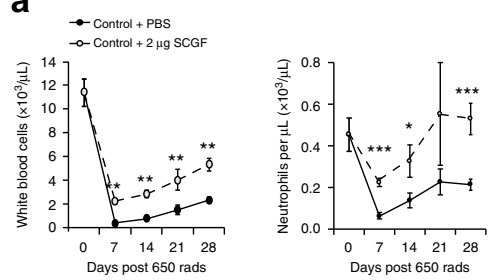

b

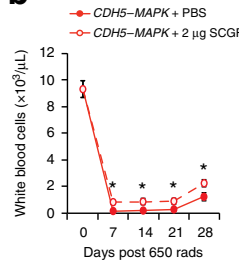

e
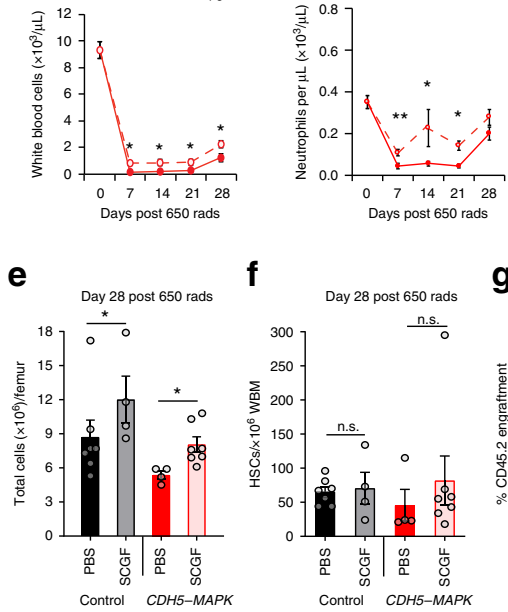
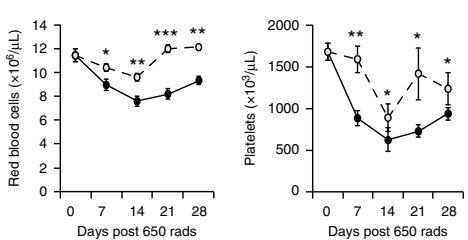

C

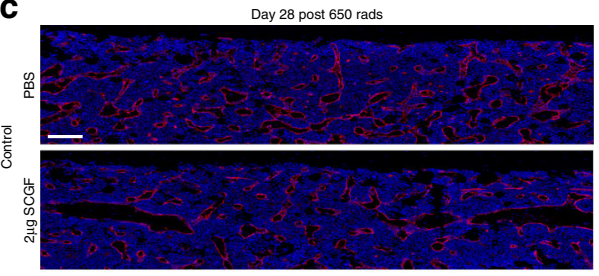

d
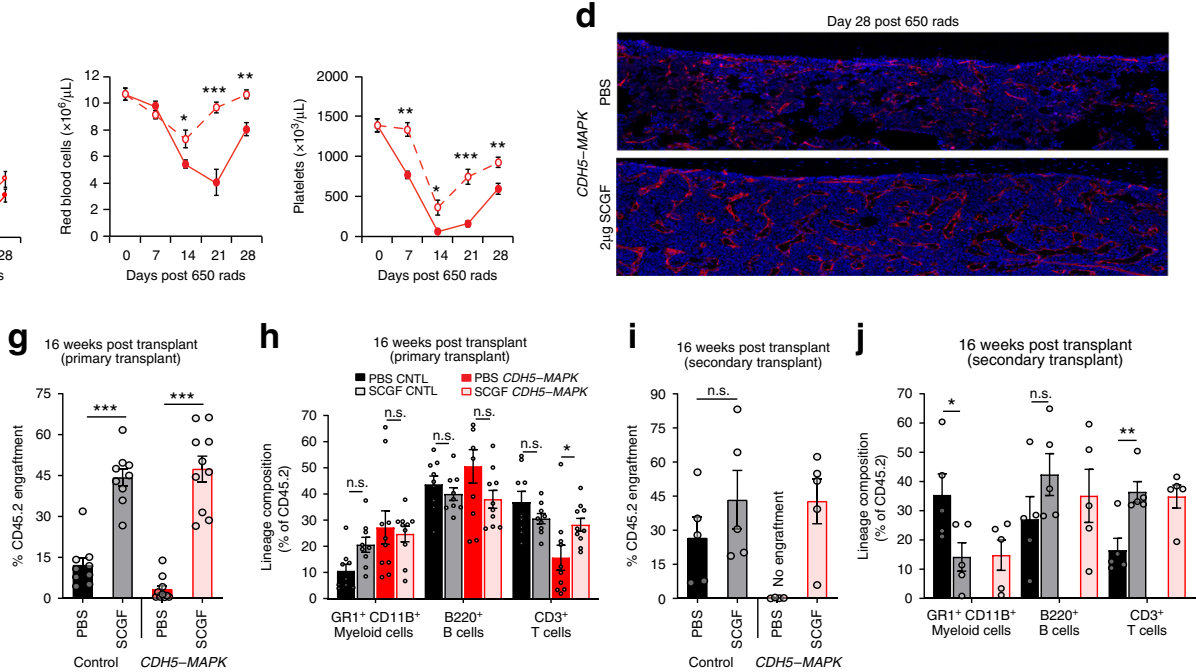

Fig. 9 SCGF enhances hematopoietic regeneration following myelosuppressive injury. a, b Following 650 rad of irradiation, $2 \mu \mathrm{g}$ of SCGF was infused on alternate days into control and CDH5-MAPK mice for a total of seven injections starting at Day +1 and hematopoietic recovery was assessed for 28 days. SCGF infusion promoted a significant increase in white blood cell, neutrophil, red blood cell, and platelet recovery at indicated time points in a control mice ( $n=6-7$ mice/cohort) as well as $\mathbf{b}$ CDH5-MAPK mice ( $n=7-8$ mice/cohort). c, $\mathbf{d}$ Representative immunofluorescence images of femurs intravitally labeled with a vascular-specific CD144/VEcadherin antibody (red) at 28 days following irradiation demonstrating that SCGF infusion improved vascular recovery in both c control mice as well as $\mathbf{d}$ CDH5-MAPK mice. e Total cells per femur ( $n=4-7$ mice/cohort). f Frequency of phenotypic HSCs per $10^{6}$ femur cells assessed by flow cytometry ( $n=4-7$ mice/cohort). $\mathbf{g}$, $\mathbf{h}$ Competitive repopulation assays assessing total CD45.2 ${ }^{+}$cell engraftment and CD45.2+ lineage distribution of donor WBM cells. Donor cells were isolated 28 days post-irradiation from PBS/SCGF-treated control and CDH5-MAPK mice. $2.5 \times 10^{6}$ donor WBM cells (CD45.2) were transplanted with $5 \times 10^{5}$ competitor WBM cells (CD45.1) into pre-conditioned CD45.1 recipient mice ( $n=9$-10 recipients/cohort; $n=5$ donors per cohort). $\mathbf{i}$, j Secondary transplantation assay wherein WBM cells from long-term engrafted primary recipients were isolated and transplanted into pre-conditioned CD45.1 recipient mice. $2 \times 10^{6}$ donor WBM cells were transplanted per secondary recipient $(n=4-5$ recipients/cohort; $n=5$ donors per cohort). Error bars represent sample mean \pm SEM. Statistical significance was determined using two-tailed unpaired Student's $t$-test. ${ }^{\star} P \leq 0.05 ;{ }^{\star \star} P<0.01 ;{ }^{\star \star \star} P<0.001 ;$ n.s. $P>0.05$.

paucity of model systems that recapitulate microenvironmentderived inflammation. In this study, we demonstrate that sustained inflammation within the BM endothelial niche adversely impacts HSC function resulting from altered oxygenation status, ROS levels, and pro-inflammatory cytokine milieu within the BM microenvironment. Activation of MAPK signaling selectively within the endothelium of adult mice drives an NF-kB dependent inflammatory stress response within the $\mathrm{BM}$ microenvironment including HSPCs and multiple niche cells, highlighting the essential role of endothelium during chronic inflammation (Fig. 10). Moreover, inflammatory stress resulting from endothelial MAPK activation caused a significant impairment in hematopoietic recovery and HSC functionality following myelosuppressive injury. Importantly, resolution of inflammation by genetic (suppression of endothelial $\mathrm{NF}-\mathrm{kB}$ ) or pharmacological (SCGF infusion) means was able to resolve all of the hematopoietic and HSC defects observed due to endothelial MAPK activation, indicating that stem cell dysfunction induced by inflammation within tissue-specific microenvironments is reversible.

It has become increasingly clear that the NF- $\kappa \mathrm{B}$ and MAPK pathways play essential roles not only in hematopoiesis, but also in modulating inflammatory responses within the microvascular endothelium ${ }^{25,32,71}$. Within ECs, NF- $\kappa B$ serves as a master regulator of a vast repertoire of pro-inflammatory cytokines ${ }^{72}$. In addition to the established roles of endothelial NF- $\kappa B$ signaling in launching immune responses against invading pathogens, it is also activated following injuries such as irradiation, leading to chronic vascular inflammation, tissue damage, and organ dysfunction 68,73 . Interestingly, NF-kB signaling within blood vessels remains activated for several years following radiation therapy, leading to sustained expression of pro-inflammatory cytokines $^{74}$. Studies have suggested that inhibiting NF- $\kappa B$ may be beneficial in protecting against myeloablative therapy, graft rejection, and graft-versus-host disease by decreasing the quantity of cytokines secreted by the graft ${ }^{32}$. Indeed, we have recently demonstrated that inhibition of the canonical NF- $\kappa$ B signaling pathway specifically in ECs has a profound impact on enhancing both steady-state hematopoiesis as well as regeneration following irradiation induced myelosuppression, in part by decreasing proinflammatory cytokines ${ }^{21}$. Recent studies have begun to illuminate the role of MAPK signaling during regeneration of the hematopoietic system, in particular when patients are exposed to moderate to high doses of total-body irradiation ${ }^{75}$. The delay in hematopoietic recovery following radiation injury has been attributed to increased MAPK signaling ${ }^{76}$. Chronic endothelial MAPK activation has been shown to cause increased vascular 


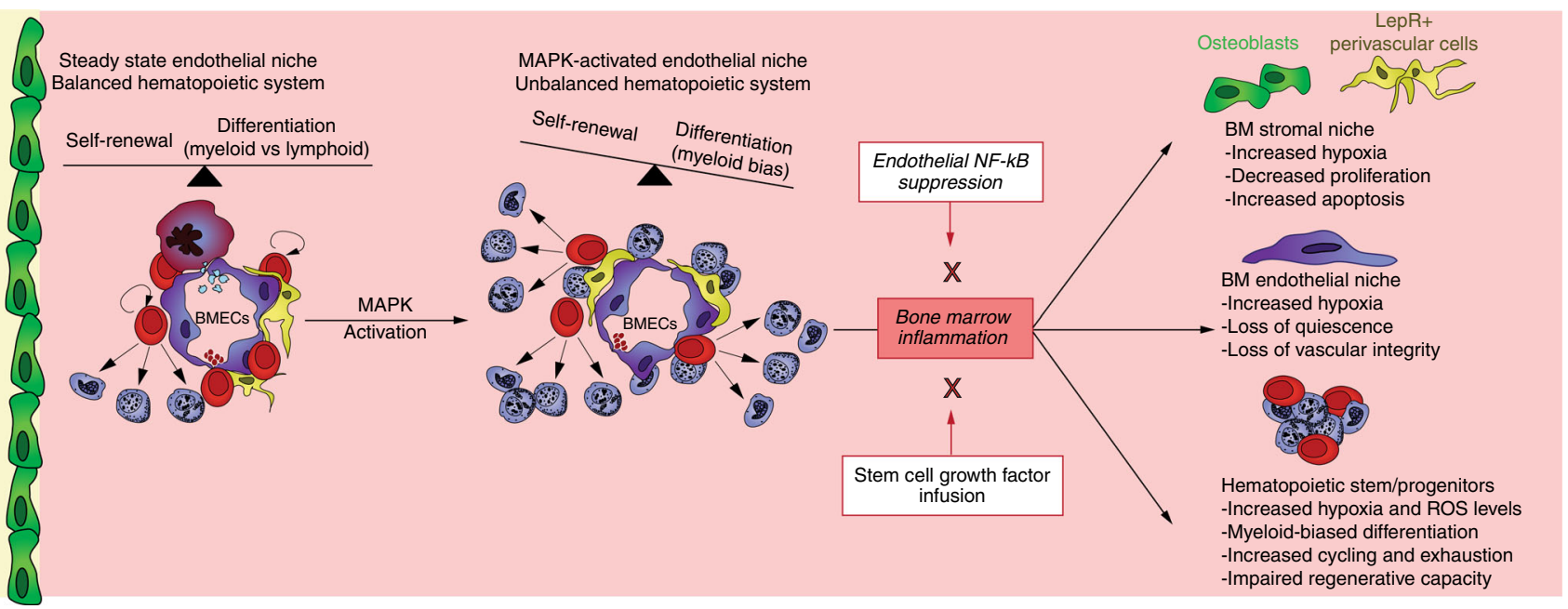

Fig. 10 Schematic describing the impact of inflammation on BM niche cells and HSPCs. Endothelial MAPK activation drives an NF-kB-dependent inflammatory stress response within the bone marrow leading to functional defects in the vascular niche and HSPCs. Suppression of inflammation by inhibition of endothelial NF-kB or infusion of SCGF restores vascular integrity, resolves HSPC and niche defects, and augments post-myelosuppressive hematopoietic recovery.

permeability, a hallmark of vascular dysfunction particularly following inflammation-induced injury 77,78 . Growing evidence suggests that MAPK activation in ECs results in increased vascular inflammation and endothelial dysfunction ${ }^{29}$. Collectively, these studies indicate that chronic inflammation within the endothelium might involve the interplay between both MAPK and NF-kB signaling pathways.

In the present study, we demonstrate that crosstalk between ERK-MAPK and NF-KB pathways regulate the outcomes of chronic endothelial inflammation within the BM and its resultant impact on niche activity and HSC function. The myeloid-biased output of HSCs observed in CDH5-MAPK mice illustrates the impact of chronic vascular inflammation on HSC function and highlights the potential of sustained niche-driven inflammation to influence aging-associated HSC phenotypes including predisposition towards myeloid neoplasms. Importantly, the complete rescue of hematopoietic defects observed in CDH5-MAPK mice upon endothelial NF-kB inhibition allows the opportunity to utilize these genetic models to derive testable hypotheses for interrogating stem cell niche interactions during chronic inflammation and to identify factors like SCGF that resolve inflammation-associated HSC and niche defects. SCGF/Clec1la is a member of the C-type lectin proteins belonging to the Tetranectin family ${ }^{79}$. Recent studies have highlighted the significant roles played by C-type lectins in the context of immunity, inflammation, and a wide array of physiological processes ${ }^{79}$. Although SCGF did not impact steady-state hematopoiesis in control mice, infusion of SCGF into CDH5-MAPK mice had tremendous benefits to the phenotypic and functional hematopoietic attributes indicating that SCGF might play key roles in mediating hematopoietic recovery under stress situations. The ability of SCGF to enhance post-myelosuppressive hematopoietic recovery in both control as well as CDH5-MAPK mice confirms its role as a rejuvenation factor during stress hematopoiesis. Considering the impact of SCGF in suppressing BM inflammation, restoring vascular integrity, promoting myelosuppressive recovery as well as its osteogenic properties, the identification of its gene regulatory mechanisms, cognate receptor/s, and downstream signaling pathways are exciting future directions. These studies will become important to understand the precise molecular mechanisms by which SCGF enhances hematopoietic regeneration and to develop treatment strategies directed towards protecting the hematopoietic system and the BM endothelial niche following myelosuppressive therapies.

\section{Methods}

Animals. C57BL/6J (CD45.2; stock no. 000664), B6.SJL-Ptprc ${ }^{a} P e p c^{b} /$ BoyJ (CD45.1; stock no. 002014), and C57BL/6-Gt(ROSA)26Sortm(Map2k1*,EGFP)Rsky/J $\mathrm{J}^{80}$ $\left(\mathrm{Mapk}^{l / f l}\right)$ (stock no. 012352) mice were purchased from The Jackson Laboratory (Bar Harbor, ME). Cdh5(PAC)-creERT2 mice (C57BL6 background) were obtained from Ralf $\mathrm{H}$. Adams at The Max Planck Institute for Molecular Biomedicine ${ }^{81}$. Tie2.IkB-SS mice (C57BL6 background) were obtained from Jan Kitajewski at Columbia University ${ }^{39}$. Lepr-cre mice (C57BL6 background) were obtained from Sean J. Morrison at the University of Texas Southwestern Medical Center ${ }^{82}$. Mapk fl/fl, Cdh5(PAC)-creERT2, Lepr-cre, and Tie2.IkB-SS mice were bred and maintained on a C57BL/6J (CD45.2) genetic background. All mice were housed in Positive Individual Ventilation (PIV) cages with HEPA-filtered air exchange (Thoren Caging Systems, Inc.) and maintained on Pico Lab Rodent Diet 20 (Lab Diet 5053) and water ad libitum. To induce Cdh5(PAC)-creERT2-mediated recombination, Tamoxifen (Sigma-Aldrich T5648) solubilized in sunflower oil (Sigma-Aldrich S5007) was administered via intraperitoneal injection (150 mg/kg body weight) at a dose of $30 \mathrm{mg} / \mathrm{mL}$ for three consecutive days at 8-12 weeks of age or fed Custom Teklad 2020 Feed supplemented with $0.025 \%$ w/w tamoxifen (Envigo) ad libitum at 6-10 weeks of age for four consecutive weeks. Age-matched cre-negative littermate mice also underwent the same tamoxifen induction regimen and were utilized as controls. Mice were allowed to recover for 4 weeks posttamoxifen induction prior to experimental analysis. All mice were maintained in specific-pathogen-free housing. Total-body $\gamma$-irradiation (TBI) was administered from a ${ }^{137} \mathrm{Cs}$ source at doses indicated in the subsequent methodology. Irradiated recipients were given PicoLab Mouse 20 antibiotic feed $(0.025 \%$ Trimethoprim and $0.124 \%$ Sulfamethoxazole; LabDiet) $24 \mathrm{~h}$ prior to irradiation and subsequently maintained for four weeks. All experiments were conducted in accordance with the Association for Assessment and Accreditation of Laboratory Animal Care, Intl. (AAALAC) and National Institutes of Health (NIH) Office of Laboratory Animal Welfare (OLAW) guidelines and under the protocols approved by Institutional Animal Care and Use Committee (IACUC) at the Center for Discovery and Innovation and Weill Cornell Medical College.

Buffers and media. Magnetic activated cell sorting (MACS) buffer: PBS without $\mathrm{Ca}^{2+} / \mathrm{Mg}^{2+}(\mathrm{pH}$ 7.2) (Corning 21-040-CV) containing 0.5\% W/V bovine serum albumin (BSA; Fisher Scientific BP1605) and 2 mM EDTA (Corning 46-034-CI).

Digestion buffer: $1 \times$ Hanks Balanced Salt Solution (Life Technologies 14065) containing $20 \mathrm{mM}$ HEPES (Corning 25-060-CI), $2.5 \mathrm{mg} / \mathrm{mL}$ Collagenase A (Roche 11088793001), and 1 unit/mL Dispase II (Roche 04942078001).

Endothelial growth medium: 1:1 ratio of low-glucose DMEM (ThermoFisher Scientific 11885-084) and Ham's F-12 (Corning 10-080), supplemented with 20\% heat-inactivated FBS (Denville Scientific FB5002-H), 1\% antibiotic-antimycotic (Corning 30-004-CI), 1\% non-essential amino acids (Corning 25-025-CI), $10 \mathrm{mM}$ HEPES (Corning 25-060-CI), $100 \mu \mathrm{g} / \mathrm{mL}$ heparin (Sigma-Aldrich H3149), and 50 $\mu \mathrm{g} / \mathrm{mL}$ EC growth supplement (Alfa Aesar BT-203)]. 
Hematopoietic, BMEC, and stromal cell quantification. To quantify total hematopoietic cells, femurs were gently crushed with a mortar and pestle and enzymatically disassociated for $15 \mathrm{~min}$ at $37^{\circ} \mathrm{C}$ in Digestion Buffer following which cell suspensions were filtered ( $40 \mu \mathrm{m}$; Corning 352340$)$ and washed in MACS buffer. Viable cell numbers were quantified using a hemocytometer with trypan blue (Life Technologies) exclusion. To quantify HSPCs in the BM, femurs and tibiae were flushed using a $26 \mathrm{G} \times 1 / 2$ needle with MACS buffer. To quantify splenic HSPCs, spleens were gently crushed and filtered over a $40 \mu \mathrm{m}$ filter to obtain single-cell suspensions. To quantify BMECs, total BM stromal cells, BM Lepr+ cells, and BM osteoblasts, femurs were gently crushed with a mortar and pestle and enzymatically disassociated for $15 \mathrm{~min}$ at $37^{\circ} \mathrm{C}$ in Digestion buffer following which cell suspensions were filtered ( $40 \mu \mathrm{m}$; Corning 352340$)$ and washed in MACS buffer. Cells were surface stained using fluorochrome-conjugated antibodies as per the manufacturer recommendations. Cell populations were analyzed using flow cytometry.

Flow cytometry. Prior to cell surface staining, $\mathrm{F}_{\mathrm{c}}$ receptors were blocked using an antibody against CD16/32 (93; Biolegend) in MACS buffer for $10 \mathrm{~min}$ at $4{ }^{\circ} \mathrm{C}$. For CMP/GMP/MEP staining, samples were blocked with $10 \%$ normal rat serum for $10 \mathrm{~min}$ at $4^{\circ} \mathrm{C}$. Blocked samples were subsequently stained with fluorochromeconjugated antibodies in MACS buffer for $30 \mathrm{~min}$ at $4{ }^{\circ} \mathrm{C}$ as described. Samples stained with biotinylated anti-Lepr antibody were washed and stained with Streptavidin-conjugated fluorochromes for $15 \mathrm{~min}$ at $4{ }^{\circ} \mathrm{C}$. Stained cells were washed in MACS buffer and fixed in 1\% paraformaldehyde (PFA) in PBS (pH 7.2) with $2 \mathrm{mM}$ EDTA. Sample data were collected and analyzed using an LSR II SORP (BD Biosciences) or Fortessa (BD Biosciences) with FACS DIVA 8.0.1 software (BD Biosciences). Gates were established using unstained controls and standard fluorescence minus one strategies. List of antibody clones utilized for flow cytometry is included in Supplementary Table 4.

Cell populations for flow cytometry and FACS sorting were defined as follows:
HSC Lineage (Ter119/CD11b/GR1/B220/CD3)

KLS $-\mathrm{CD} 41-\mathrm{cKIT}+\mathrm{SCA} 1+\mathrm{CD} 48-\mathrm{CD} 150+$ Lineage-cKIT + SCA1+

MPP Lineage $-\mathrm{cKIT}+\mathrm{SCA} 1+\mathrm{CD} 48-\mathrm{CD} 150-$

HPC-1 Lineage - cKIT + SCA1 + CD $48+\mathrm{CD} 150-$

HPC-2 Lineage - cKIT + SCA1 + CD $48+C D 150+$ Lineage-cKIT ${ }^{\text {low }}$ SCA $1^{\text {low }}$ FLT3+IL7Ra+

CMP Lineage - cKIT + SCA1 $-\mathrm{CD} 34+\mathrm{CD} 16 / 32-$

GMP Lineage-cKIT+SCA1-CD34+CD16/32+

MEP Lineage-cKIT+SCA1-CD34-CD16/32-

Pre Pro B sIgM-B220+CD43+CD24-

Pro B sIgM-B220+CD43+CD24+

Pre B sIgM-B220+CD43-CD24+

Myeloid $\quad \mathrm{CD} 45+\mathrm{CD} 11 \mathrm{~B}+\mathrm{GR} 1+$

B cells $\quad$ CD $45+B 220+$

$\mathrm{T}$ cells $\quad \mathrm{CD} 45+\mathrm{CD} 3+$

BMECs CD45-Ter119-CD31+VEcadherin+

BM CD45-Ter119-CD31-VEcadherin-

stromal cells

BM CD45-Ter119-CD31-Lepr+

Lepr+ cells

CD45-Ter119-CD31-SCA1-CD51+
BM
osteoblasts
Gating strategy in Fig.

$1 \mathrm{c}$ Gating strategy in Fig. 1c Gating strategy in Fig. 1c Gating strategy in Fig. 1c

Gating strategy in Fig. 1c

Gating strategy in Supplementary Fig. 2e Gating strategy in Supplementary Fig. 2e Gating strategy in Supplementary Fig. 2e Gating strategy in Supplementary Fig. 2e Gating strategy in Supplementary Fig. $2 \mathrm{f}$ Gating strategy in Gating strategy in Supplementary Fig. $2 \mathrm{f}$ Supplementary Fig. 2b Gating strategy in Supplementary Fig. 2b Gating strategy in Supplementary Fig. 2b Gating strategy in Supplementary Fig. 6a Gating strategy in Supplementary Fig. 6a Gating strategy in Supplementary Fig. 6b Gating strategy in Supplementary Fig. 6c Supplementary Fig. $2 \mathrm{f}$ Gating strategy in

Progenitor activity. Colony-forming units (CFUs) in semi-solid methylcellulose were quantified to assess hematopoietic progenitor activity. WBM was flushed from femurs and tibiae using a $26 \mathrm{G} \times 1 / 2$ needle with MACS buffer. Viable cell counts were determined with a hemocytometer using Trypan Blue (Life Technologies). WBM cells $\left(5 \times 10^{4}\right.$ cells/well) were plated in duplicate in Methocult GF M3434 methylcellulose (StemCell Technologies) according to the manufacturer's suggestions. Colonies were scored for phenotypic CFU-GEMM, CFU-GM, CFU-G, CFU-M, and BFU-E colonies using a SZX16 stereo-microscope (Olympus).

Competitive transplantation and limiting dilutions. Adult CD45.1 recipient mice were pre-conditioned with lethal irradiation (950 rad) $16 \mathrm{~h}$ prior to transplantation WBM was isolated from femurs by gently crushing with a mortar and pestle and was enzymatically disassociated for $15 \mathrm{~min}$ at $37^{\circ} \mathrm{C}$ in Digestion buffer following which cell suspensions were filtered $(40 \mu \mathrm{m}$; Corning 352340$)$ and washed in MACS to obtain single-cell suspensions. Viable cell numbers were quantified using a hemocytometer with Trypan Blue (Life Technologies) for live/dead exclusion. For competitive transplantation experiments at steady state (1:1 ratio), $5 \times 10^{5}$ donor WBM cells (CD45.2) were transplanted with $5 \times 10^{5}$ competitor WBM cells (CD45.1) via retro-orbital sinus injections into CD45.1 recipient mice preconditioned with myeloablative irradiation (950 rads). For competitive transplantation experiments following myelosuppressive injury (5:1 ratio), $2.5 \times 10^{6}$ donor WBM cells (CD45.2) were transplanted with $5 \times 10^{5}$ competitor WBM cells (CD45.1). Retro-orbital sinus bleeds using $75 \mathrm{~mm}$ heparinized glass capillary tubes (Kimble-Chase) were used to assess multi-lineage hematopoietic engraftment. Peripheral blood was depleted of red blood cells using RBC Lysis Buffer (Biolegend 420301) and stained with fluorochrome-conjugated antibodies according to the manufacturer's recommendations. Hematopoietic engraftment antibody panel includes CD45.1 (A20; Biolegend), CD45.2 (104; Biolegend), and TER119 (TER119; Biolegend). Multi-lineage engraftment panels include CD45.2 (104; Biolegend), GR1 (RB6-8C5; Biolegend), CD11B (M1/70; Biolegend), B220 (RA36B2; Biolegend), CD3 (17A2; Biolegend), CD4 (GK1.5; Biolegend), and CD8 (536.7; Biolegend). For limiting dilution analysis, indicated numbers of WBM were non-competitively transplanted via retro-orbital sinus injections into preconditioned CD45.1 recipient mice. Percent negative responding/dead mice were monitored for a four-month post-transplant period. Multi-lineage hematopoietic engraftment in surviving mice was confirmed by flow cytometry in red blood cell (RBC)-lysed peripheral blood using antibodies raised against CD45.2 (104; Biolegend), GR1 (RB6-8C5; Biolegend), CD11B (M1/70; Biolegend), B220 (RA3-6B2; Biolegend), and CD3 (17A2; Biolegend). HSC frequency and statistical significance was calculated using Extreme Limiting Dilution Analysis (ELDA) software (http:// bioinf.wehi.edu.au/software/elda/ $)^{83}$.

Vascular permeability. Bone marrow vascular integrity was examined as follows. $0.5 \%$ w/v Evans Blue Dye (Sigma-Aldrich E2129) in PBS ( $\mathrm{pH} 7.2$ ) was injected via tail vein at $25 \mathrm{mg}$ dye $/ \mathrm{kg}$ total body weight. Three hours post-injection, mice were sacrificed via cervical dislocation and cardiac perfused with $10 \mathrm{~mL}$ PBS ( $\mathrm{pH} 7.2$ ). Femurs were crushed in a mortar and pestle with $600 \mu \mathrm{L}$ formamide and incubated at $55^{\circ} \mathrm{C}$ overnight. Extractions were briefly vortexed and centrifuged at $16,000 \times g$ for $5 \mathrm{~min}$ at room temperature. Supernatant was removed and absorbance (Abs) was measured at 620 and $740 \mathrm{~nm}$. Sample Abs was corrected for heme-containing proteins $\left[\mathrm{Abs}_{620}-\left(1.426 \times \mathrm{Abs}_{740}+0.03\right)\right]$ and blanked using non-injected controls [corrected sample $\mathrm{Abs}_{620}$-corrected non-injected control $\mathrm{Abs}_{620}$ ]. Evan's blue dye extravasation was calculated using a standard curve and normalized to femur weight.

Immunohistochemistry. To label the vasculature, mice were intravenously administered $25 \mu \mathrm{g}$ of Alexa Fluor 647-conjugated CD144/VEcadherin antibody (Clone BV13; Biolegend) via retro-orbital sinus injections. Animals were sacrificed $10 \mathrm{~min}$ post-injection and cardiac perfused with $10 \mathrm{~mL}$ PBS (pH 7.2). Femurs were

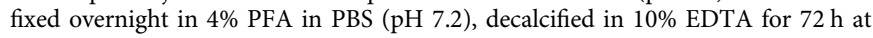
room temperature, cryopreserved in $30 \%$ sucrose for $48 \mathrm{~h}$ at $4{ }^{\circ} \mathrm{C}$, and embedded in $50 \%$ optimal cutting temperature (OCT) and 50\% sucrose. Longitudinal femur sections $(12 \mu \mathrm{m})$ were cut using a CM 3050S Cryostat (Leica), counterstained with $1 \mu \mathrm{g} / \mathrm{mL}$ 4-6,diamidino-2-phenylindole (DAPI) (Biolegend), and mounted using Prolong Gold anti-fade solution (Life Technologies). Sections were imaged on a LSM 710 confocal microscope (Zeiss).

Whole-mount immunofluorescence. Mice were intravenously administered $25 \mu \mathrm{g}$ of Alexa Fluor 647-conjugated CD144/VEcadherin antibody (Clone BV13; Biolegend) via retro-orbital sinus injections. After $10 \mathrm{~min}$, mice were euthanized and cardiac perfused with $4 \%$ PFA following which femurs were isolated, stripped of muscle and connective tissue, and fixed in 4\% PFA for $30 \mathrm{~min}$ at room temperature. Bones were washed in $1 \times$ PBS $3 \times 5 \mathrm{~min}$ and cryopreserved in $15 \%$ sucrose for $24 \mathrm{~h}$ at $4{ }^{\circ} \mathrm{C}$, and further cryopreserved in $30 \%$ sucrose for $24 \mathrm{~h}$ at $4{ }^{\circ} \mathrm{C}$. Bones were then embedded in a 50\% OCT and 50\% sucrose solution and flash frozen in liquid nitrogen. Bones were shaved longitudinally on a Leica CM 3050S cryostat in order to fully expose the bone marrow cavity for antibody penetration. Shaved bones were unmounted and washed $3 \times 5 \mathrm{~min}$ in $1 \times$ PBS until OCT was completely melted. Exposed bones were blocked for $2 \mathrm{~h}$ at room temperature in blocking buffer [20\% normal goat serum (Jackson Laboratories) in $1 \times$ PBS containing $0.5 \%$ Triton $\mathrm{X}-100]$, protected from light. Bones were then stained with fluorochromeconjugated primary antibodies (Supplementary Table 5) diluted in blocking buffer by immersion incubation in $1.5 \mathrm{~mL}$ Eppendorf microcentrifuge tubes for $48 \mathrm{~h}$ at $4^{\circ}$ C. Bones were washed $3 \times 10 \mathrm{~min}$ in $1 \times$ PBS. Forty-micrometer Z-stack images were acquired on a Nikon C2 confocal laser scanning microscope. HSCs were 
defined by Lineage ${ }^{\text {neg }} \mathrm{CD} 48^{\text {neg }} \mathrm{CD} 150^{\text {bright }}$ cells and their distance relative to the nearest vascular cell (VE-cadherin/CD144+) was measured for quantification.

Proteomic analysis. Plasma proteome analysis was performed at SomaLogic (Boulder, CO) using the aptamer-based SomaScan platform ${ }^{84}$. To generate plasma, mice were bled via the retro-orbital sinus using $75 \mathrm{~mm}$ heparinized glass capillary tubes (Kimble-Chase) into EDTA containing microcentrifuge tubes $(5 \mu \mathrm{M}$ final concentration). Whole blood was centrifuged at $2200 \times g$ for $15 \mathrm{~min}$ at room temperature and plasma was collected and stored at $-80^{\circ} \mathrm{C}$. Cryopreserved mouse plasma-EDTA samples were analyzed using the SomaScan Assay $1.1 \mathrm{~K}$ platform and proteomic data are presented as relative fluorescent units (RFUs). To identify differentially expressed proteins, two-sided Student's $t$-test was performed with the threshold of significance set at $P \leq 0.075$ using SomaSuite Software (SomaLogic). Core analysis was performed on the entire dataset $(P$ value cut-off $\leq 0.05$, Fisher's exact test) using Ingenuity Pathway Analysis (Qiagen) to identify biological processes that are significantly enriched in CDH5-MAPK mice. (https://www. qiagenbioinformatics.com/products/ingenuity-pathway-analysis/).

Lentivirus. Myristoylated-Akt1 (myrAkt1) lentivirus was generated by cotransfecting $p C C L-m y r A k t 1$ backbone ${ }^{15}(13 \mu \mathrm{g})$ with RRE $(5 \mu \mathrm{g})$, REV $(2.5 \mu \mathrm{g})$, and VSV-G $(3 \mu \mathrm{g})$ packaging plasmids on a $10 \mathrm{~cm}$ dish of $80 \%$ confluent $293 \mathrm{~T} / 17$ cells (ATCC CRL-11268) using Lipofectamine 2000 (ThermoFisher Scientific 12566014) according to the manufacturer's suggestions. Forty-eight hours post-transfection, supernatants were processed using a Lenti-X Concentrator (ClonTech 631232) according to the manufacturer's suggestions. Precipitated myrAkt1 lentivirus was resuspended in $0.5 \mathrm{~mL}$ TNE Buffer $(50 \mathrm{mM}$ Tris pH 8.0, $1 \mathrm{mM}$ EDTA, $130 \mathrm{mM} \mathrm{NaCl}$ ), aliquoted, and stored at $-80^{\circ} \mathrm{C}$. Viral titers were determined using Lenti-X p24 Rapid Titer Kit (ClonTech 632200). IkB-SS expressing lentiviral vector was generated by sub-cloning the sequence of human IкBa super-suppressor (Addgene \#15264) into pLVX Puro Vector (Clontech \#632164). IkB-SS lentivirus was generated by co-transfecting pLVX-Puro-IkB-SS vector with RRE, REV, and VSV-G packaging plasmids in 293T cells as described earlier. pLVX Puro Vector (Clontech \#632164) was utilized to generate the "Puro-empty" lentivirus.

EC cultures. Primary BMEC cultures were generated from Cdh5(PAC)-creERT2

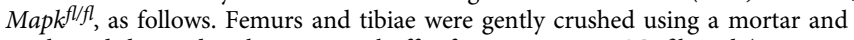
pestle and digested with Digestion buffer for $15 \mathrm{~min}$ at $37^{\circ} \mathrm{C}$, filtered $(40 \mu \mathrm{m}$; Corning 352340), and washed in MACS buffer. WBM was depleted of terminally differentiated hematopoietic cells using a murine Lineage Cell Depletion Kit (Miltenyi Biotec 130-090-858) according to the manufacturer's recommendations. BM endothelium was immunopurified from cell suspensions using sheep anti-rat IgG Dynabeads (ThermoFisher Scientific 11035) pre-captured with a CD31 antibody (MEC13.3; Biolegend) in MACS buffer according to the manufacturer's suggestions. CD31 selected BMECs were cultured in endothelial growth media and transduced with $10^{4} \mathrm{pg} m y r A k t 1$ lentivirus per $3 \times 10^{4} \mathrm{ECs} / \mathrm{cm}^{2}$. Akt-transduced BMECs were selected for 7 days in serum- and cytokine-free StemSpan SFEM (StemCell Technologies, Inc. 09650) media. BMEC lines were stained with antibodies against VECAD (BV13; Biolegend), CD31 (390; Biolegend), and CD45 (30F11; Biolegend) and FACS sorted for purity (BMEC defined as CD45- CD31+ VEcadherin + ). Established BMEC lines were transduced either with GFP lentivirus (Control BMECs) or GFP-Cre lentivirus (CDH5-MAPK BMECs) and the resultant GFP+ cells were FACS sorted to purity. Control and CDH5-MAPK BMECs were subsequently transduced with either Puro-empty or Puro-IKB-SS lentivirus to generate, respectively, Control, IkB, CDH5-MAPK, and CDH5-MAPK::IkB cell lines. Transduced cell lines were selected with $2 \mu \mathrm{g} / \mathrm{mL}$ puromycin for 5 days. Cells were cultured in endothelial growth medium at $37^{\circ} \mathrm{C}, 5 \% \mathrm{CO}_{2}$, and $20 \% \mathrm{O}_{2}$ in $70 \%$ relative humidity. Growth media was changed every 2 days and cells were passaged 1:2 at 95\% confluency with Accutase Cell Detachment Solution (Biolegend 423201) according to the manufacturer's suggestions.

Immunoblots. Established BMEC lines were serum starved in low-glucose DMEM for $36 \mathrm{~h}$ prior to preparing cell lysates. Cultured cells were washed with ice-cold PBS (pH 7.2) and lysed in RIPA buffer ( $150 \mathrm{mM} \mathrm{NaCl}, 1 \%$ IGEPAL CA-630, $0.5 \%$ deoxycholate, $0.1 \%$ sodium dodecyl sulfate (SDS), and $50 \mathrm{mM}$ Tris- $\mathrm{HCl}, \mathrm{pH} 8.0$ ) with PhosStop Phosphatase Inhibitor (Roche 04906845001) and Complete EDTAfree Protease Inhibitor Cocktail (Roche 11836170001 ) for $20 \mathrm{~min}$ at $4^{\circ} \mathrm{C}$, sonicated, and centrifuged for $10 \mathrm{~min}$ at $21,000 \times g$ at $4^{\circ} \mathrm{C}$ to remove insoluble debris. Supernatants were stored at $-80^{\circ} \mathrm{C}$. Protein concentrations were determined using the DC Protein Assay (BioRad 5000111) and $5 \mu \mathrm{g}$ total protein was denatured for 3 min at $95^{\circ} \mathrm{C}$ in Laemmli Buffer, resolved on $12.5 \%$ SDS-acrylamide gels, and electroblotted to nitrocellulose. Transferred blots were blocked for $1 \mathrm{~h}$ in $5 \%$ nonfat dry milk in PBS (pH 7.2) with 0.05\% IGEPAL CA-630 (Sigma-Aldrich I8896) and incubated overnight at $4{ }^{\circ} \mathrm{C}$ in $5 \%$ non-fat dry milk in PBS (pH 7.2) with $0.05 \%$ IGEPAL CA-630 with primary antibodies raised against phospho-p65 (Ser536) at 1:1000 (Cell Signaling 3033), p65 at 1:1000 (Cell Signaling 4764), phospho-ERK1/2 (Thr202/Tyr204) at 1:2000 (Cell Signaling 4370), ERK1/2 at 1:1000 (Cell Signaling 9102), Total IкBa at 1:1000 (Cell Signaling 4814), and Tubulin at 1:1000 (Cell Signaling 2146). Blots were washed $3 \times 10 \mathrm{~min}$ in PBS (pH 7.2) with $0.05 \%$ IGEPAL $\mathrm{CA}-630$ at room temperature and incubated in $5 \%$ non-fat dry milk in PBS $(\mathrm{pH}$
7.2) with $0.05 \%$ IGEPAL CA-630 and anti-rabbit or anti-mouse IgG $(\mathrm{H}+\mathrm{L})$ horseradish peroxidase (Jackson ImmunoResearch Laboratories) secondary antibodies at a dilution of 1:10,000 for $1 \mathrm{~h}$ at room temperature. Blots were washed $3 \times$ $10 \mathrm{~min}$ in PBS (pH 7.2) with 0.05\% IGEPAL CA-630 at room temperature and developed using Amersham ECL Prime Western Blotting Detection Reagent (GE Healthcare RPN2232), according to the manufacturer's suggestions. All blots were developed using Carestream Kodak BioMax Light Film (Sigma-Aldrich).

Quantification of nuclear p65. For assessment of nuclear p65, BMECs were plated in endothelial growth medium in chamber slides (Nunc Lab-Tek II CC ${ }^{2}$ Chamber Slide; Catalog \# 154941). At $70 \%$ confluency, cells were serum starved in lowglucose DMEM for $36 \mathrm{~h}$ following which cells were washed in PBS (pH 7.2) and fixed in 4\% PFA in PBS (pH 7.2) for 15 min at room temperature. Cells were then permeabilized with $5 \%$ normal goat serum containing $1 \%$ Triton X-100 in PBS $(\mathrm{pH}$ 7.2) for $30 \mathrm{~min}$. Cells were then stained with p65 antibody (C22B4; Cell Signaling, 1:100 dilution) in antibody dilution buffer ( $1 \%$ Triton $^{\text {nt }} \mathrm{X}-100$ in PBS containing $1 \%$ BSA) for $1 \mathrm{~h}$ at room temperature. Cells were washed three times with PBS and stained with goat anti-rabbit Alexa Fluor 647 (Thermo Scientific \#A-21245, 1:250 dilution) in antibody dilution buffer for $30 \mathrm{~min}$ at room temperature. Cells were washed three times with PBS and counterstained with DAPI at $1 \mu \mathrm{g} / \mathrm{mL}$ and mounted using Prolong Gold anti-fade solution (Life Technologies). To determine the effect of SCGF on nuclear p65 levels, BMECs derived from CDH5-MAPK mice were incubated with $0.4 \mu \mathrm{g} / \mathrm{mL}$ SCGF (or vehicle control) for $36 \mathrm{~h}$ in low-glucose DMEM. Concentration-matched isotype control antibody (Cell Signaling \#3900) was used for establishing background fluorescence. Images were acquired on a Nikon C2 confocal laser scanning microscope. Nuclear p65 levels were quantified using Image J by measuring mean fluorescence intensity of p65 in every nucleus demarcated by DAPI staining ${ }^{36}$.

Gene expression analysis. WBM was flushed from femurs and tibiae using a $26 \mathrm{G} \times 1 / 2$ needle with MACS buffer and depleted of red blood cells using $1 \times \mathrm{RBC}$ Lysis Buffer (Biolegend 420301) according to the manufacturer's recommendations. Total RNA was isolated from $4 \times 10^{6} \mathrm{RBC}$-lysed WBM cells using RNeasy plus Mini Kit (Qiagen 74134) according to the manufacturer's instructions. Briefly, cells were lysed in $600 \mu \mathrm{L}$ of Buffer RLT and homogenized using QIAshredder columns (Qiagen 79654). For RNA isolation from CD45 cells, stromal cells, Lepr+ cells, and osteoblasts, cells were directly sorted into Trizol LS using FACS and RNA was purified using the manufacturer's recommendations. RNA was isolated from 100,000 CD 45 + cells per sample and 1000 cells per sample for stromal cells, Lepr+ cells, and osteoblasts. For WBM and CD45 cells, total RNA was reverse transcribed using RT2 First Strand Kit (Qiagen 330401). cDNA generated from $100 \mathrm{ng}$ total RNA was subsequently loaded on to RT2 PCR profiler arrays to evaluate gene expression of NF-kB signaling targets (Qiagen PAMM-225ZC). For stromal cells, Lepr + cells, and osteoblasts, cDNA was generated and amplified using the Ovation Pico WTA System V2 (Nugen) according to the manufacturer's suggested protocol and $100 \mathrm{ng}$ amplified CDNA was utilized for the qPCR arrays. qPCR was performed using RT2 SYBR Green qPCR Mastermix (Qiagen 330522) in a ViiA 7 qPCR system (Applied Biosystems) with recommended cycling parameters. Qiagen's online data analysis tool was utilized to calculate fold changes, generate unsupervised hierarchical clustering, and gene expression heatmaps (https://www. qiagen.com/in/shop/genes-and-pathways/data-analysis-center-overview-page/). Reference genes for normalization were selected from a panel of five housekeeping genes (Actb, B2m, Gapdh, Gusb, and Hsp90a1b) using "automatic selection of housekeeping genes" in the Qiagen online tool which selects the most stable reference gene for each condition. Fold changes were calculated using the $2^{-\Delta \Delta C T}$ method. Confirmation of $I l 1 b$ and Csfl expression was performed by RT-qPCR using primers obtained from Qiagen (Cat \# PPM03109F-200 and PPM03116C 200). Primers for RT-qPCR analysis are listed in Supplementary Table 6. For evaluation of cre and IkB-SS transgene expression in hematopoietic cells, RNA was isolated from 100,000 CD45+ cells per sample. Total RNA was reverse transcribed using RT2 First Strand Kit (Qiagen 330401). cDNA equivalent to RNA content of 2000 cells was utilized for RT-PCR analysis. Primers for RT-PCR analysis are listed in Supplementary Table 6.

Peripheral hematopoietic recovery. Mice were irradiated with sublethal irradiation $(650 \mathrm{rad})$ from a ${ }^{137} \mathrm{Cs}$ source for evaluating hematopoietic recovery following myelosuppressive injury. Peripheral blood was collected using $75 \mathrm{~mm}$ heparinized glass capillary tubes (Kimble-Chase) via retro-orbital sinus bleeds at indicated time points. $\mathrm{WBC}, \mathrm{RBC}$, and platelet populations were analyzed using an Advia120 (Bayer Healthcare).

ROS estimation. To examine ROS, mice were intravitally labeled for $10 \mathrm{~min}$ with $25 \mu \mathrm{g}$ Alexa Fluor 647-conjugated CD144/VE-Cadherin antibody (BV13; Biolegend) via retro-orbital injection. Mice were sacrificed and femurs were either flushed (for HSPC analysis) or gently crushed and enzymatically disassociated (for BMEC and stromal cell analysis) in Digestion buffer for $15 \mathrm{~min}$ at $37^{\circ} \mathrm{C}$ with gentle agitation. Cell suspensions were filtered $(40 \mu \mathrm{m})$ and washed in MACS buffer followed by surface staining using the indicated antibodies for $20 \mathrm{~min}$ at $4{ }^{\circ} \mathrm{C}$. Stained cell suspensions were washed in MACS buffer and then incubated with 5 
$\mu \mathrm{M}$ CellROX Orange (ThermoFisher Scientific) in Stemspan SFEM (StemCell Technologies) at $37^{\circ} \mathrm{C}$ for $30 \mathrm{~min}$, washed with MACS buffer, and resuspended in PBS containing $2 \mathrm{mM}$ EDTA. ROS levels in the indicated cell types were estimated using flow cytometry.

Hypoxyprobe. To evaluate bone marrow oxygenation status, mice were co-injected with $100 \mathrm{mg} / \mathrm{kg}$ of Pimonidazole $\mathrm{HCl}$ (hypoxyprobe-1; Hypoxyprobe, Inc.) and 25 $\mu \mathrm{g}$ Alexa Fluor 647-conjugated CD144/VE-Cadherin (BV13; Biolegend) via retroorbital injection. Following $20 \mathrm{~min}$, mice were euthanized and femurs were isolated. Femurs were either flushed (for HSPC analysis) or gently crushed and enzymatically disassociated (for BMEC and stromal cell analysis) in Digestion buffer for 15 $\min$ at $37^{\circ} \mathrm{C}$ with gentle agitation. Following surface staining, cells were fixed and permeabilized using the BD Cytofix/Cytoperm Kit (BD Biosciences) and stained with a monoclonal antibody raised against hypoxyprobe-1 at a 1:100 dilution (HPRed549; Hypoxyprobe, Inc.) according to the manufacturer's suggestions.

Hypoxyprobe levels in the indicated cell types were estimated using flow cytometry.

Cell cycle and apoptosis. For cell-cycle analysis of BMECs, stromal cells, and HSPCs, cells were surface stained, fixed, and permeabilized using the BD Cytofix/ Cytoperm Kit (BD Biosciences) as described in the preceding section following which the cells were stained with an antibody raised against Ki67 (B56, BD 561284) and counterstained with Hoechst 33342 (BD Biosciences), according to the manufacturer's recommendations. For cell-cycle analysis of HSCs, WBM cells were first depleted of lineage-positive cells using a lineage cell depletion kit (Miltenyi Biotec \# 130-110-470) prior to surface staining. Cell were analyzed using flow cytometry with a low acquisition rate (350 events/s). Cell-cycle status was classified as follows: G0 (Ki-67 ${ }^{\text {negative, }}$ 2N DNA content), G1 (Ki-67+; 2N DNA content), and S/G2/M (Ki-67+; $>2 \mathrm{~N}$ DNA content). Percentage of singlet cells in the sub-G0/G1 area were classified as apoptotic.

Plasma ELISA. For aptamer-based sandwich ELISAs, streptavidin-coated 96-well plates (ThermoFisher Scientific 15124) were incubated at $4{ }^{\circ} \mathrm{C}$ overnight with 20 nM biotinylated aClec1la aptamer (SomaLogic; Boulder, CO Cat\# B-4500-50_2) in SBT buffer ( $40 \mathrm{mM}$ HEPES pH 7.5, $120 \mathrm{mM} \mathrm{NaCl}, 5 \mathrm{mM} \mathrm{KCl}, 5 \mathrm{mM} \mathrm{MgCl}_{2}$, and $0.05 \%$ Tween-20) according to the manufacturer's recommendations. Plates were washed three times with SBT buffer and blocked with $100 \mu \mathrm{M}$ biotin (SigmaAldrich B4501) in SBT buffer for $10 \mathrm{~min}$ at room temperature. Plates were washed three times at 100 RPM for 1 min with SBT buffer and blocked with 3\% BSA in SBT buffer for $30 \mathrm{~min}$ at room temperature. Plates were washed three times at 100 RPM for 1 min with SBT buffer. Mouse plasma biological replicates were diluted 1:80 in SBT buffer (optimal plasma dilution range determined in-house) and incubated at $450 \mathrm{RPM}$ for $2 \mathrm{~h}$ at $37^{\circ} \mathrm{C}$. SBT alone was used to determine background signal. Plates were then washed three times at 100 RPM for $1 \mathrm{~min}$ in TBST buffer (Tris- $\mathrm{HCl} \mathrm{pH} \mathrm{7.6,} 150 \mathrm{mM} \mathrm{NaCl}, 0.05 \%$ Tween-20) and incubated at 450 RPM for $1 \mathrm{~h}$ at room temperature with $1 \mu \mathrm{g} / \mathrm{mL}$ aClec1la polyclonal antibody (R\&D Systems AF3729) in 3\% BSA in TBST buffer. Plates were washed three times at $100 \mathrm{RPM}$ for $1 \mathrm{~min}$ in TBST buffer and incubated at $450 \mathrm{RPM}$ for $30 \mathrm{~min}$ at room temperature with $8 \mathrm{ng} / \mathrm{mL}$ peroxidase-conjugated donkey-agoat secondary antibody (Jackson ImmunoResearch 705-035-147) in 3\% BSA in TBST buffer (optimal secondary antibody dilution range determined in-house). Plates were washed three times at 100 RPM for $1 \mathrm{~min}$ in TBST buffer and incubated in 1-Step Ultra TMB substrate (ThermoFisher Scientific 34028) for $12 \mathrm{~min}$ at room temperature. Sulfuric acid was added to a final concentration of $1 \mathrm{M}$ to stop the reaction and absorbance was read at $450 \mathrm{~nm}$.

Direct ELISAs were performed as follows. Mouse plasma was diluted 1:50 in PBS ( $\mathrm{pH}$ 7.2) (optimal plasma dilution range determined in-house to achieve a maximum signal-to-noise ratio) and coated on Corning $1 \times 8$ Stripwell 96-well plates (Sigma-Aldrich CLS2592) and incubated overnight at $4{ }^{\circ} \mathrm{C}$. PBS (pH 7.2) alone was used to determine background signal. Plates were washed three times in PBS (pH 7.2) with $0.01 \%$ Tween-20 and blocked for $2 \mathrm{~h}$ at room temperature with ELISA Blocker blocking buffer (ThermoFisher Scientific N502). Plates were washed three times in PBS (pH 7.2) with 0.01\% Tween-20 and incubated for $2 \mathrm{~h}$ at room temperature with $1 \mu \mathrm{g} / \mathrm{mL}$ aClec1la polyclonal antibody (R\&D Systems AF3729) in PBS (pH 7.2) with $0.01 \%$ Tween-20. Following primary antibody incubation, plates were washed three times in PBS (pH 7.2) with $0.01 \%$ Tween-20 and incubated for $1 \mathrm{~h}$ at room temperature with $8 \mathrm{ng} / \mathrm{mL}$ peroxidase-conjugated donkey-agoat secondary antibody (Jackson ImmunoResearch 705-035-147) in PBS ( $\mathrm{pH}$ 7.2) with $0.01 \%$ Tween-20 (optimal secondary antibody dilution range determined in-house). Plates were then washed three times in PBS ( $\mathrm{pH}$ 7.2) with $0.01 \%$ Tween-20 and incubated in 1-Step Ultra TMB substrate (ThermoFisher Scientific 34028) for $12 \mathrm{~min}$ at room temperature. Sulfuric acid was added to a final concentration of $1 \mathrm{M}$ to stop the reaction and absorbance was read at $450 \mathrm{~nm}$. Recombinant murine Clec1la protein (R\&D Systems 3729-SC/CF) was used to establish standard curves and determine protein concentration.

Clec11a/SCGF infusion. Recombinant murine Clec11a (SCGF) protein (R\&D Systems 3729-SC/CF) was resuspended in PBS (pH 7.2) to $100 \mu \mathrm{g} / \mathrm{mL}$ and stored at $-80^{\circ} \mathrm{C}$ as single-use aliquots. For steady-state analysis, $100 \mu \mathrm{L}$ of either $4 \mu \mathrm{g} \mathrm{SCGF}$ in PBS ( $\mathrm{pH}$ 7.2) or PBS alone was injected subcutaneously on five consecutive days prior to analysis. Total SCGF protein dosing in steady-state animals was adapted from a previous report ${ }^{62}$. For regeneration analysis, $100 \mu \mathrm{L}$ of either $2 \mu \mathrm{g}$ SCGF in PBS (pH 7.2) or PBS alone was injected subcutaneously on days 1, 3, 5, 7, 9, 11, and 13 post-TBI ( 650 rads). SCGF dosing following myelosuppressive injury was determined by a dose-response experiment (Supplementary Fig. 10).

$\boldsymbol{\mu C T}$ analysis. Femurs were isolated, fixed in $4 \%$ PFA for $24 \mathrm{~h}$ at $4{ }^{\circ} \mathrm{C}$, and stored in $70 \%$ ethanol at $4{ }^{\circ} \mathrm{C}$. A Scanco Medical $\mu \mathrm{CT} 35$ system with an isotropic voxel size of $7 \mu \mathrm{m}$ was used to image the distal femur. Scans used an X-ray tube potential of $55 \mathrm{kVp}$, an X-ray intensity of $0.145 \mathrm{~mA}$, and an integration time of $600 \mathrm{~ms}$. For trabecular bone analysis, an upper $2.1-\mathrm{mm}$ region beginning $280 \mu \mathrm{m}$ proximal to the growth plate was contoured. For cortical bone analysis, a region $0.6 \mathrm{~mm}$ in length centered on the mid-shaft was used. Trabecular and cortical bones were thresholded at 211 and 350 per $\mathrm{mg} \mathrm{HA} / \mathrm{cm}^{3}$, respectively. 3D images were obtained from contoured $2 \mathrm{D}$ images by methods based on distance transformation of the binarized images.

Statistics. Sample sizes for phenotypic and functional analysis of mouse hematopoietic parameters were determined based on prior estimates of variance and effect sizes observed in previous experiments. Number of animals needed were calculated based on the ability to detect a two-fold change in the mean with $80 \%$ power, with the threshold for significance $(\alpha)$ set at 0.05 . All experimental findings were confirmed in at least two independent cohorts of mice and the data presented in the manuscript represent pooled data from independent experiments. Statistical comparisons between two groups were performed using two-tailed Student's $t$-test. Multiple comparisons were made using a one-way ANOVA analysis with a Tukey's correction. Data are presented as the mean \pm standard error of the mean (SEM), unless otherwise noted. Statistical significance is indicated as ${ }^{*}(P<0.05),{ }^{* *}(P<$ $0.01),{ }^{* * *}(P<0.001)$, and n.s. (not significant). Statistical analysis was performed using Prism 6 (GraphPad Software). HSC frequency and 95\% confidence intervals were determined using ELDA software (http://bioinf.wehi.edu.au/software/elda/) ${ }^{83}$.

Reporting summary. Further information on research design is available in the Nature Research Reporting Summary linked to this article.

\section{Data availability}

The authors declare that data supporting the findings of this study are available within the manuscript and its Supplementary Information files. Source data for Figs. 1-9 and Supplementary Figs. 1-10 are provided with the paper as a Source Data File. Proteomics raw data are included in Supplementary Data 1. Proteomics Raw Data are included in the Source Data File.

Received: 10 April 2019; Accepted: 13 January 2020; Published online: 03 February 2020

\section{References}

1. Wagers, A. J. The stem cell niche in regenerative medicine. Cell Stem Cell 10, 362-369 (2012)

2. Lane, S. W., Williams, D. A. \& Watt, F. M. Modulating the stem cell niche for tissue regeneration. Nat. Biotechnol. 32, 795-803 (2014).

3. Schepers, K., Campbell, T. B. \& Passegue, E. Normal and leukemic stem cell niches: insights and therapeutic opportunities. Cell Stem Cell 16, 254-267 (2015).

4. Baldridge, M. T., King, K. Y. \& Goodell, M. A. Inflammatory signals regulate hematopoietic stem cells. Trends Immunol. 32, 57-65 (2011).

5. Zhao, J. L. \& Baltimore, D. Regulation of stress-induced hematopoiesis. Curr. Opin. Hematol. 22, 286-292 (2015)

6. Boettcher, S. \& Manz, M. G. Regulation of inflammation- and infection-driven hematopoiesis. Trends Immunol. 38, 345-357 (2017).

7. Espin-Palazon, R., Weijts, B., Mulero, V. \& Traver, D. Proinflammatory signals as fuel for the fire of hematopoietic stem cell emergence. Trends Cell Biol. 28, 58-66 (2018).

8. Bowers, E. et al. Granulocyte-derived TNFalpha promotes vascular and hematopoietic regeneration in the bone marrow. Nat. Med. 24, 95-102 (2018).

9. Kovtonyuk, L. V., Fritsch, K., Feng, X., Manz, M. G. \& Takizawa, H. Inflammaging of hematopoiesis, hematopoietic stem cells, and the bone marrow microenvironment. Front. Immunol. 7, 502 (2016).

10. Pietras, E. M. et al. Chronic interleukin-1 exposure drives haematopoietic stem cells towards precocious myeloid differentiation at the expense of self-renewal. Nat. Cell Biol. 18, 607-618 (2016).

11. Lussana, F. \& Rambaldi, A. Inflammation and myeloproliferative neoplasms. J. Autoimmun. 85, 58-63 (2017)

12. Pietras, E. M. Inflammation: a key regulator of hematopoietic stem cell fate in health and disease. Blood 130, 1693-1698 (2017). 
13. Hooper, A. T. et al. Engraftment and reconstitution of hematopoiesis is dependent on VEGFR2-mediated regeneration of sinusoidal endothelial cells. Cell Stem Cell 4, 263-274 (2009).

14. Butler, J. M. et al. Endothelial cells are essential for the self-renewal and repopulation of Notch-dependent hematopoietic stem cells. Cell Stem Cell 6, 251-264 (2010).

15. Kobayashi, H. et al. Angiocrine factors from Akt-activated endothelial cells balance self-renewal and differentiation of haematopoietic stem cells. Nat. Cell Biol. 12, 1046-1056 (2010).

16. Winkler, I. G. et al. Vascular niche E-selectin regulates hematopoietic stem cell dormancy, self renewal and chemoresistance. Nat. Med. 18, 1651-1657 (2012).

17. Ding, L., Saunders, T. L., Enikolopov, G. \& Morrison, S. J. Endothelial and perivascular cells maintain haematopoietic stem cells. Nature 481, 457-462 (2012).

18. Poulos, M. G. et al. Endothelial jagged-1 is necessary for homeostatic and regenerative hematopoiesis. Cell Rep. 4, 1022-1034 (2013).

19. Greenbaum, A. et al. CXCL12 in early mesenchymal progenitors is required for haematopoietic stem-cell maintenance. Nature 495, 227-230 (2013).

20. Doan, P. L. et al. Epidermal growth factor regulates hematopoietic regeneration after radiation injury. Nat. Med. 19, 295-304 (2013).

21. Poulos, M. G. et al. Endothelial-specific inhibition of NF-kappaB enhances functional haematopoiesis. Nat. Commun. 7, 13829 (2016).

22. Kusumbe, A. P. et al. Age-dependent modulation of vascular niches for haematopoietic stem cells. Nature 532, 380-384 (2016).

23. Morrison, S. J. \& Scadden, D. T. The bone marrow niche for haematopoietic stem cells. Nature 505, 327-334 (2014)

24. Rafii, S., Butler, J. M. \& Ding, B. S. Angiocrine functions of organ-specific endothelial cells. Nature 529, 316-325 (2016).

25. Pober, J. S. \& Sessa, W. C. Evolving functions of endothelial cells in inflammation. Nat. Rev. Immunol. 7, 803-815 (2007).

26. Boettcher, S. et al. Endothelial cells translate pathogen signals into G-CSFdriven emergency granulopoiesis. Blood 124, 1393-1403 (2014).

27. Wang, L. et al. Notch-dependent repression of miR-155 in the bone marrow niche regulates hematopoiesis in an NF-kappaB-dependent manner. Cell Stem Cell 15, 51-65 (2014).

28. Sanchez, A. et al. Map3k8 controls granulocyte colony-stimulating factor production and neutrophil precursor proliferation in lipopolysaccharideinduced emergency granulopoiesis. Sci. Rep. 7, 5010 (2017).

29. Roth Flach, R. J. et al. Endothelial protein kinase MAP4K4 promotes vascular inflammation and atherosclerosis. Nat. Commun. 6, 8995 (2015).

30. Vandoorne, K. et al. Imaging the vascular bone marrow niche during inflammatory stress. Circ. Res. 123, 415-427 (2018).

31. Baker, R. G., Hayden, M. S. \& Ghosh, S. NF-kappaB, inflammation, and metabolic disease. Cell Metab. 13, 11-22 (2011).

32. Bottero, V., Withoff, S. \& Verma, I. M. NF-kappaB and the regulation of hematopoiesis. Cell Death Differ. 13, 785-797 (2006)

33. Brown, K., Park, S., Kanno, T., Franzoso, G. \& Siebenlist, U. Mutual regulation of the transcriptional activator NF-kappa B and its inhibitor, I kappa B-alpha. Proc. Natl Acad. Sci. USA 90, 2532-2536 (1993).

34. Wu, C. \& Ghosh, S. Differential phosphorylation of the signal-responsive domain of I kappa B alpha and I kappa B beta by I kappa B kinases. J. Biol. Chem. 278, 31980-31987 (2003).

35. Yang, F., Tang, E., Guan, K. \& Wang, C. Y. IKK beta plays an essential role in the phosphorylation of RelA/p65 on serine 536 induced by lipopolysaccharide. J. Immunol. 170, 5630-5635 (2003).

36. Wessel, A. W. \& Hanson, E. P. A method for the quantitative analysis of stimulation-induced nuclear translocation of the p65 subunit of NF-kappaB from patient-derived dermal fibroblasts. Methods Mol. Biol. 1280, 413-426 (2015).

37. Boehm, J. S. et al. Integrative genomic approaches identify IKBKE as a breast cancer oncogene. Cell 129, 1065-1079 (2007).

38. Brown, K., Gerstberger, S., Carlson, L., Franzoso, G. \& Siebenlist, U. Control of I kappa B-alpha proteolysis by site-specific, signal-induced phosphorylation. Science 267, 1485-1488 (1995).

39. Kisseleva, T. et al. NF-kappaB regulation of endothelial cell function during LPS-induced toxemia and cancer. J. Clin. Invest. 116, 2955-2963 (2006).

40. Wei, Q. \& Frenette, P. S. Niches for hematopoietic stem cells and their progeny. Immunity 48, 632-648 (2018).

41. Crane, G. M., Jeffery, E. \& Morrison, S. J. Adult haematopoietic stem cell niches. Nat. Rev. Immunol. 17, 573-590 (2017).

42. Comazzetto, S. et al. Restricted hematopoietic progenitors and erythropoiesis require SCF from leptin receptor+ niche cells in the bone marrow. Cell Stem Cell 24, 477-486.e476 (2019).

43. Inra, C. N. et al. A perisinusoidal niche for extramedullary haematopoiesis in the spleen. Nature 527, 466-471 (2015).

44. Sorensen, I., Adams, R. H. \& Gossler, A. DLL1-mediated Notch activation regulates endothelial identity in mouse fetal arteries. Blood 113, 5680-5688 (2009).
45. Langen, U. H. et al. Cell-matrix signals specify bone endothelial cells during developmental osteogenesis. Nat. Cell Biol. 19, 189-201 (2017).

46. Payne, S., De Val, S. \& Neal, A. Endothelial-specific Cre mouse models. Arterioscler Thromb. Vasc. Biol. 38, 2550-2561 (2018).

47. Kilani, B. et al. Comparison of endothelial promoter efficiency and specificity in mice reveals a subset of Pdgfb-positive hematopoietic cells. J. Thromb. Haemost. 17, 827-840 (2019).

48. Forde, A., Constien, R., Grone, H. J., Hammerling, G. \& Arnold, B. Temporal Cre-mediated recombination exclusively in endothelial cells using Tie2 regulatory elements. Genesis 33, 191-197 (2002).

49. Tang, Y., Harrington, A., Yang, X., Friesel, R. E. \& Liaw, L. The contribution of the Tie2+ lineage to primitive and definitive hematopoietic cells. Genesis 48, 563-567 (2010).

50. Gareus, R. et al. Endothelial cell-specific NF-kappaB inhibition protects mice from atherosclerosis. Cell Metab. 8, 372-383 (2008).

51. Korhonen, H. et al. Anaphylactic shock depends on endothelial Gq/G11. J. Exp. Med. 206, 411-420 (2009).

52. Bartels, K., Grenz, A. \& Eltzschig, H. K. Hypoxia and inflammation are two sides of the same coin. Proc. Natl Acad. Sci. USA 110, 18351-18352 (2013).

53. Karhausen, J., Haase, V. H. \& Colgan, S. P. Inflammatory hypoxia: role of hypoxia-inducible factor. Cell Cycle 4, 256-258 (2005).

54. Eltzschig, H. K. \& Carmeliet, P. Hypoxia and inflammation. N. Engl. J. Med 364, 656-665 (2011).

55. Mittal, M., Siddiqui, M. R., Tran, K., Reddy, S. P. \& Malik, A. B. Reactive oxygen species in inflammation and tissue injury. Antioxid. Redox Signal. 20 1126-1167 (2014)

56. Bigarella, C. L., Liang, R. \& Ghaffari, S. Stem cells and the impact of ROS signaling. Development 141, 4206-4218 (2014).

57. Takubo, K. et al. Regulation of the HIF-lalpha level is essential for hematopoietic stem cells. Cell Stem Cell 7, 391-402 (2010).

58. Ludin, A. et al. Reactive oxygen species regulate hematopoietic stem cell selfrenewal, migration and development, as well as their bone marrow microenvironment. Antioxid. Redox Signal. 21, 1605-1619 (2014).

59. Zhou, B. O., Yue, R., Murphy, M. M., Peyer, J. G. \& Morrison, S. J. Leptinreceptor-expressing mesenchymal stromal cells represent the main source of bone formed by adult bone marrow. Cell Stem Cell 15, 154-168 (2014).

60. Ding, L. \& Morrison, S. J. Haematopoietic stem cells and early lymphoid progenitors occupy distinct bone marrow niches. Nature 495, 231-235 (2013).

61. Mossadegh-Keller, N. et al. M-CSF instructs myeloid lineage fate in single haematopoietic stem cells. Nature 497, 239-243 (2013).

62. Yue, R., Shen, B. \& Morrison, S. J. Clec11a/osteolectin is an osteogenic growth factor that promotes the maintenance of the adult skeleton. Elife 5, https://doi. org/10.7554/eLife.18782 (2016).

63. Keller, C. C. et al. Suppression of a novel hematopoietic mediator in children with severe malarial anemia. Infect. Immun. 77, 3864-3871 (2009).

64. Ito, C. et al. Serum stem cell growth factor for monitoring hematopoietic recovery following stem cell transplantation. Bone Marrow Transplant. 32 391-398 (2003).

65. Mazumder, B., Li, X. \& Barik, S. Translation control: a multifaceted regulator of inflammatory response. J. Immunol. 184, 3311-3319 (2010).

66. McDermott, B. T., Peffers, M. J., McDonagh, B. \& Tew, S. R. Translational regulation contributes to the secretory response of chondrocytic cells following exposure to Interleukin-1beta. J. Biol. Chem. https://doi.org/10.1074/ jbc.RA118.006865 (2019).

67. Li, X. M., Hu, Z., Jorgenson, M. L., Wingard, J. R. \& Slayton, W. B. Bone marrow sinusoidal endothelial cells undergo nonapoptotic cell death and are replaced by proliferating sinusoidal cells in situ to maintain the vascular niche following lethal irradiation. Exp. Hematol. 36, 1143-1156 (2008).

68. Baselet, B., Sonveaux, P., Baatout, S. \& Aerts, A. Pathological effects of ionizing radiation: endothelial activation and dysfunction. Cell Mol. Life Sci. 76, 699-728 (2019).

69. Zhang, H. et al. Sepsis induces hematopoietic stem cell exhaustion and myelosuppression through distinct contributions of TRIF and MYD88. Stem Cell Rep. 6, 940-956 (2016).

70. Mirantes, C., Passegue, E. \& Pietras, E. M. Pro-inflammatory cytokines: emerging players regulating HSC function in normal and diseased hematopoiesis. Exp. Cell Res. 329, 248-254 (2014).

71. Geest, C. R. \& Coffer, P. J. MAPK signaling pathways in the regulation of hematopoiesis. J. Leukoc. Biol. 86, 237-250 (2009).

72. Xiao, L., Liu, Y. \& Wang, N. New paradigms in inflammatory signaling in vascular endothelial cells. Am. J. Physiol. Heart Circ. Physiol. 306, H317-H325 (2014).

73. Korpela, E. \& Liu, S. K. Endothelial perturbations and therapeutic strategies in normal tissue radiation damage. Radiat. Oncol. 9, 266 (2014).

74. Halle, M. et al. Sustained inflammation due to nuclear factor-kappa B activation in irradiated human arteries. J. Am. Coll. Cardiol. 55, 1227-1236 (2010). 
75. Munshi, A. \& Ramesh, R. Mitogen-activated protein kinases and their role in radiation response. Genes Cancer 4, 401-408 (2013).

76. Wang, Y., Liu, L. \& Zhou, D. Inhibition of p38 MAPK attenuates ionizing radiation-induced hematopoietic cell senescence and residual bone marrow injury. Radiat. Res. 176, 743-752 (2011).

77. Dong, F. et al. Cadmium induces vascular permeability via activation of the p38 MAPK pathway. Biochem. Biophys. Res. Commun. 450, 447-452 (2014).

78. Li, L. et al. P38/MAPK contributes to endothelial barrier dysfunction via MAP4 phosphorylation-dependent microtubule disassembly in inflammationinduced acute lung injury. Sci. Rep. 5, 8895 (2015).

79. Brown, G. D., Willment, J. A. \& Whitehead, L. C-type lectins in immunity and homeostasis. Nat. Rev. Immunol. 18, 374-389 (2018).

80. Srinivasan, L. et al. PI3 kinase signals BCR-dependent mature B cell survival. Cell 139, 573-586 (2009).

81. Benedito, R. et al. The notch ligands Dll4 and Jagged1 have opposing effects on angiogenesis. Cell 137, 1124-1135 (2009).

82. DeFalco, J. et al. Virus-assisted mapping of neural inputs to a feeding center in the hypothalamus. Science 291, 2608-2613 (2001).

83. Hu, Y. \& Smyth, G. K. ELDA: extreme limiting dilution analysis for comparing depleted and enriched populations in stem cell and other assays. $J$. Immunol. Methods 347, 70-78 (2009).

84. Gold, L. et al. Aptamer-based multiplexed proteomic technology for biomarker discovery. PLoS ONE 5, e15004 (2010).

\section{Acknowledgements}

We would like to thank the Starr Foundation Tri-Institutional Core Facilities. Our work is supported by the Tri-Institutional Stem Cell Initiative (2014-004), American Society of Hematology Scholar Award, American Federation for Aging Research, National Institutes of Health (1R01CA204308 and 1R01HL133021), and the Leukemia and Lymphoma Society Quest for Cures. Jason M. Butler is a Scholar of The Leukemia and Lymphoma Society.

\section{Author contributions}

P.R. designed the experiments; analyzed hematopoietic parameters including transplantations and myelosuppressive studies; performed proteomic and transcriptional profiling and analysis; performed direct ELISAs and immunoblots; analyzed all data and helped prepare the manuscript. E.L. and M.G.P. helped design the experiments; analyzed vascular leakiness and performed aptamer-based Sandwich ELISAs; helped with functional assays; helped analyze the data and prepare the manuscript. D.L. helped design the experiments; performed SCGF infusion studies; helped analyze hematopoietic parameters; helped analyze the data and prepare the manuscript. C.C.K. helped design the experiments and executed steady-state hematopoietic assays. M.J.C. analyzed SomaLogic proteomic analysis and conducted Ingenuity Pathway Analysis. M.C.G. and L.K. conducted immunofluorescence analysis, helped with functional assays and maintained and generated all animal models. M.B.G. conducted bone $\mu \mathrm{CT}$ analysis. M.C.G., L.K., A.G.F., and C.Y.P. helped with the functional assays. P.R. and J. M.B. designed the experiments, was responsible for the overall project strategy and management, helped execute all phenotypic and functional hematopoietic assays, and prepared the manuscript.

\section{Competing interests}

The authors declare no competing interests.

\section{Additional information}

Supplementary information is available for this paper at https://doi.org/10.1038/s41467020-14478-8.

Correspondence and requests for materials should be addressed to J.M.B.

Peer review information Nature Communication thanks John Chute and other, anonymous, reviewer(s) for their contributions to the peer review of this work. Peer review reports are available.

Reprints and permission information is available at http://www.nature.com/reprints

Publisher's note Springer Nature remains neutral with regard to jurisdictional claims in published maps and institutional affiliations.

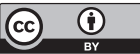

Open Access This article is licensed under a Creative Commons Attribution 4.0 International License, which permits use, sharing, adaptation, distribution and reproduction in any medium or format, as long as you give appropriate credit to the original author(s) and the source, provide a link to the Creative Commons license, and indicate if changes were made. The images or other third party material in this article are included in the article's Creative Commons license, unless indicated otherwise in a credit line to the material. If material is not included in the article's Creative Commons license and your intended use is not permitted by statutory regulation or exceeds the permitted use, you will need to obtain permission directly from the copyright holder. To view a copy of this license, visit http://creativecommons.org/ licenses/by/4.0/.

(C) The Author(s) 2020 